QUANTIFYING THE EFFECT OF LOCAL SHELTER ON TREE GROWTH PATTERNS WITHIN UPPER TREELINE ECOTONES IN THE BIGHORN MOUNTANS OF WYOMING.

A Thesis
presented to
the Faculty of the Graduate School
at the University of Missouri-Columbia
In Partial Fulfillment
of the Requirements for the Degree
Master of Arts
by by
Dr. Grant P. Elliott, Thesis Supervisor

July 2017 
CC Copyright by Nathan Mackley 2017

All Rights Reserved 
The undersigned, appointed by the dean of the Graduate School, have examined the entitled,

QUANTIFYING THE EFFECT OF LOCAL SHELTER ON TREE GROWTH PATTERNS WITHIN UPPER TREELINE ECOTONES IN THE BIGHORN MOUNTANS OF WYOMING.

presented by Nathan Mackley,

a candidate for the degree of Master of Arts in Geography

and hereby certify that, in their opinion, it is worthy of acceptance.

Professor Grant P. Elliott

Professor Rose-Marie Muzika

Professor Michael A. Urban 
Thank you to all of my family for their encouragement and support throughout the years. Thank you to George and Andy for always allowing me talk to excess about tree data and still being willing to hang out with me. Thanks to Ron for his advice and encouragement. And thank you to Nicole and Beth, whose love for trees is greater than even my own. 


\section{ACKNOWLEDGEMENTS}

I would like to thank Dr. Grant Elliott for his help and continued support throughout the years in completing this research. Thank you to Dr. Rose-Marie Muzika and Dr. Michael Urban for their great advice, critique, and their willingness to help. Thank you also to Dr. Michael Stambaugh and Joe Marschall for their guidance and use of the Missouri Tree-Ring Laboratory to complete my analysis. I am extremely grateful to you all. 


\section{TABLE OF CONTENTS}

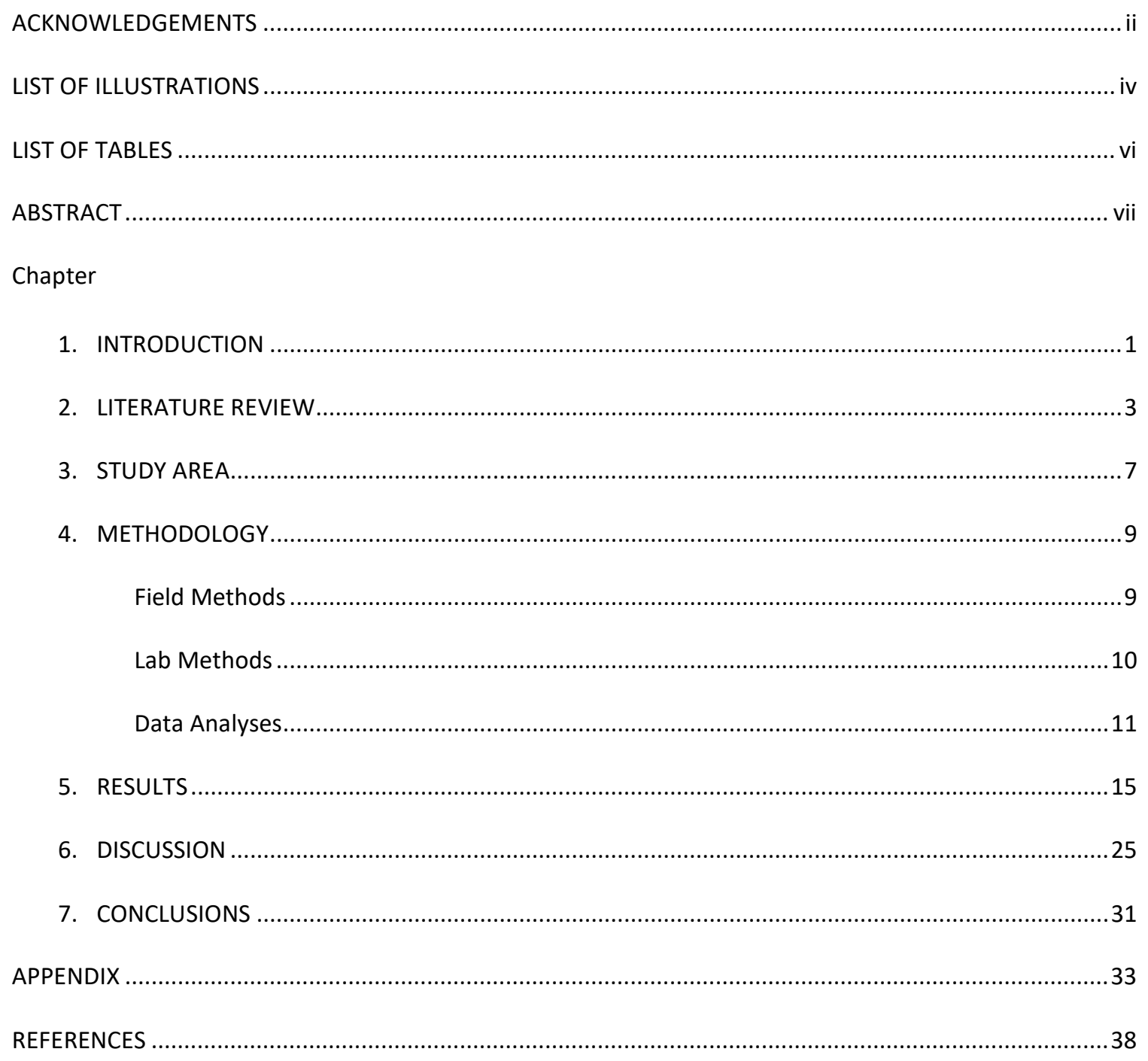


$\begin{array}{lll}\text { Figure } & \text { Page }\end{array}$

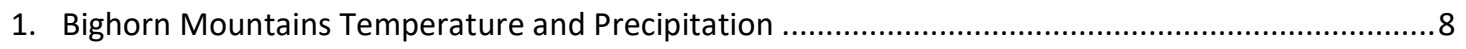
a. Average Maximum Temperature
b. Mean Annual Temperature
c. Average Minimum Temperature
d. Total Annual Precipitation
e. Cool Season (November - May) Precipitation

2. Bruce Mountain Age Structure 16

Bruce Mountain North - Sheltered Establishment

Bruce Mountain North - Non-sheltered Establishment

Bruce Mountain South - Sheltered Establishment

Bruce Mountain South - Non-sheltered Establishment

3. Basal Area Index

Bruce Mountain North

Bruce Mountain South (excluding samples established prior to 1970)

4. Basal Area Index - Bruce Mountain South (total samples)

5. Bruce Mountain North - Establishment, Species, and Growth

19
a. Plot of sampled trees by sheltered / open establishment
b. Plot of sampled trees by species
c. Basal Area Index (BAI) of sampled trees by elevation
d. Annual Basal Area Index of sampled trees by species and elevation

6. Bruce Mountain South - Establishment, Species, and Growth

a. Plot of sampled trees by sheltered / open establishment

b. Plot of sampled trees by species 

c. Basal Area Index (BAI) of sampled trees by elevation
d. Annual Basal Area Index of sampled trees by species and elevation

7. Spatial Pattern Analysis of Bruce Mountain North and Bruce Mountain South
a. Ripley's K (L(r)) Analysis
b. Pair Density Function $(g(r))$ Analysis
c. Multivariate marked (L12(r)) Analysis 


\section{LIST OF TABLES}

Table

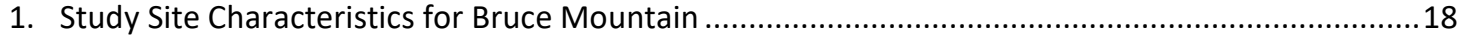

2. Pearson Correlation of Tree Growth by Species and Elevational Gradient .................................30 


\title{
QUANTIFYING THE EFFECT OF LOCAL SHELTER ON TREE GROWTH PATTERNS WITHIN UPPER TREELINE ECOTONES IN THE BIGHORN MOUNTANS OF WYOMING.
}

\author{
Nathan Mackley \\ Dr. Grant P. Elliott, Thesis Supervisor
}

ABSTRACT

On Bruce Mountain in the Bighorn Mountains of Wyoming, the upper treeline ecotone has advanced upslope since 1970 and to the highest extent in at least the past 210 years. However, the mechanisms facilitating tree establishment and treeline advance during this time were distinctly different between north and south-facing slope aspects. Tree regeneration on the south-facing slope was predominantly confined to microsites in the sheltered lee of boulders where more shade, moisture retention, and protection from the wind exist. Trees on the north-facing slope colonized open alpine tundra and facilitated continued regeneration clustered in close proximity to these trees. Thus, while patterns of tree establishment and treeline advance are well understood, it remains unknown whether differences in tree growth exist between these two sites. This is relevant as other studies suggest that favorable climatic conditions for tree establishment do not correspond with periods of high annual growth rates for trees at upper treeline. The goal of this research was to determine whether distinct patterns of tree establishment influence annual growth rates of these trees. To address this, I calculated basal area increment (BAI) for all trees positioned above the upper forest border. Surprisingly, annual growth rates and corresponding BAI values were almost identical between sites since 1970. These results suggest that tree establishment may be more of a critical limiting factor to upper treeline advance than tree growth because consistent growth patterns were found irrespective of spatial pattern on opposite slope aspects. From spatial pattern analysis, tree establishment on the northern slope adheres to the known biological preferences for each of the treeline species; while the pattern of establishment on the southern slope is overridden by the availability of favorable sites (i.e. in the lee of boulders) providing needed shade and moisture retention. As the treeline is a temperature and moisture-limited ecotone, there are observed differences along the elevational gradient within the site and between species that grow open and have a higher drought tolerance compared to those that rely on shade and neighboring trees. 


\section{INTRODUCTION}

With unprecedented increases in global temperature during the last half of the $20^{\text {th }}$ century (IPCC 2013), the interaction of large-scale climate changes with local topography becomes invaluable to understand recent changes in climate-vegetation interactions. It had been argued that with increasing temperatures there would be corresponding shift in treeline position upslope (Vaganov 1999). In fact, a meta-analysis of studies in conducted in treeline ecotones in recent decades revealed a slight majority (52\%) have observed an advance in treeline position worldwide since 1900 (Harsch et al. 2009), though climatic conditions during periods that benefit tree regeneration are often inversely correlated with periods that favor for annual growth (Daniels and Veblen 2004; Holtmeier and Broll 2005; Fajardo and Mclntire 2012). With a recorded increase in annual temperature since $1950\left(0.13^{\circ} \mathrm{C} \pm 0.03^{\circ} \mathrm{C}\right.$ per decade $)$ and a forecasted continued increase (Mann et al 2008; IPCC 2013), it is necessary to identify those factors that impact growth.

Growth at treeline has revealed varying reactions to moisture and temperature limitations depending on the scale of study: whether across mountain ranges (Lloyd and Fastie 2002; Kipfmueller and Salzer 2010; Bunn et al. 2011), between opposing slope aspects (Wang 2013; Shrestha 2015), and along an elevational gradient from treeline downslope into subalpine forest (Liang 2014; Salzer et al. 2014). Differences in slope aspect can impact solar insolation and moisture retention (Villalba et al. 1994; Bunn et al. 2005) creating generally cool, moist north-facing and warm, dry southern-facing slopes in the northern hemisphere. These differing conditions have been found to encourage unique spatial patterns of establishment. Clustered growth in a dry environment may provide needed shade and moisture retention while trees established without the same stresses are able to establish in the open. Treeline advance is often contingent on sheltered microsites to enable upslope establishment (Bekker 2005; Resler et al. 2005; Holtmeier and Broll, 2007; Kullman and Öberg 2009). Existing shelter by trees or topographic barriers can then initiate a positive feedback for subsequent growth by providing additional areas protected from climatic stresses. 
The spatial patterns of tree establishment within upper treeline ecotones have been studied in previous research (Humphries et al. 2008; Elliott and Kipfmueller 2010; Elliott 2011; Harsch and Bader 2011; Bourgeron et al. 2015), although there has been less discussion of how these measured patterns influence radial growth of trees. The impact of temperature and moisture limitation can change throughout time as temperature increases surpass a threshold where moisture is not sufficient to support continued growth (e.g., Moyes et al. 2005). Studies have already found indications that increasing annual temperature is reducing snowpack during the cool season resulting in moisture stress in treeline environments (Lloyd and Fastie 2002; Daniels and Veblen 2004; Wang 2006; Danby and Hik 2007; Elliott 2011; Elliott and Cowell 2015).

On Bruce Mountain in the Bighorn Mountains of Wyoming, treeline has experienced upslope advancement in since 1970 unlike any in the past 210 years (Elliott 2012a). From data collected above timberline on the opposing north and south-facing aspects, it has been shown that while the upslope advancement has been significant compared to historical levels and they display similar clustered growth patterns, the mechanisms facilitating this new establishment were distinctly different. Regeneration on the south-facing slope favored establishment in the lee of topographical features whereas trees on the north-facing slope colonized open tundra with subsequent regeneration in close proximity to these trees. Since aspect appears to be a primary controlling factor for habitable sites on the southern aspect of Bruce Mountain, this supports the idea that microclimatic conditions have encouraged seedling development (e.g., Germino et al. 2002) but it is not certain how growth of mature trees has been impacted. Similar spatial clustering on the northern site involving shade-tolerant species may indicate a need for moisture retention (Elliott and Kipfmueller 2010; Elliott 2011; Elliott and Cowell 2015) at both locations. Given that the trees sampled in the Bighorns were part of an unprecedented upslope shift and the decades following, trends in radial growth will reveal if overall site conditions have continued to support favorable tree growth since establishment.

This research describes how the evolving spatial structure of these upper treeline ecotones impacts annual patterns of radial growth. By using the basal area increment (BAI) of sampled trees derived from 
annual radial growth, species composition, and the location of each sampled tree on each site; it is possible to recreate the pattern and timing of establishment, and amount of woody growth produced during each year. Comparing growth of individual trees between slope aspects, tree species, and across the elevational gradient of each site will help identify what limiting factors exist for future treeline growth. I hypothesize that due to increasing temperatures, the clustered spatial pattern found on both aspects will allow for significant radial growth; however, the northern aspect will exhibit a greater amount of growth as it will be alleviated from the moisture stress of the southern aspect caused by solar exposure.

\section{LITERATURE REVIEW}

The alpine treeline ecotone is the zone between the treeline, the elevational limit of upright tree growth, and the timberline or the upper elevational limit of the closed canopy forest (Malanson 2007). Due to environmental lapse rates, air temperature cools with increasing elevation. When a threshold is reached, temperature begins to limit the biophysical processes allowing for radial growth of treeline species. An annual average soil temperature of $6.7^{\circ} \mathrm{C}$ was found to be common to treeline locations regardless of latitude (Körner 2004); since treeline occurs at lower elevations with increasing latitude as areas closer to the poles have limited solar receipt and shortened growing seasons. Those trees that are able to establish near this limit exist under regular but fluctuating stresses of harsh weather conditions that affect the behavior of growth. Thus, this limit is not a static line but a zone that is acted on by changes in seasonal temperature and precipitation receipt (Lamarche 1973), changing climatic conditions (Vaganov 1999; Körner 2004; Smith et al. 2009; Elliott and Cowell 2015), and local topographic variables (Holtmeier and Broll 2005, Butler et al. 2007; Malanson 2007; Elliott 2011; Bunn et al. 2011; Elliott 2012b). Due to the location at this edge of favorable growing conditions, small fluctuations in seasonal conditions will greatly impact the radial growth of annual rings (Lamarche 1973), the production of seedlings (Daniels and Velblen 2004; Elliott and Cowell 2015), and where seedlings are able to establish (Holtmeier and Broll 2005; Butler et al. 2007; Harsch and Bader 2011; Fajardo and Mclntire 2012). The potential location for seedling establishment fluctuates, sometimes rapidly, with dramatic changes to environmental conditions 
(Allen and Breshears 1998). This makes the treeline environment a sensitive indicator of how trees can react under changing climatic conditions. Current findings on global trends indicate that average temperatures have risen since $1850\left(0.76^{\circ} \mathrm{C} \pm 0.19^{\circ} \mathrm{C}\right)$ with temperatures increasing at twice the average over the past fifty years $\left(0.13^{\circ} \mathrm{C} \pm 0.03^{\circ} \mathrm{C}\right.$ per decade). With forecasted conditions indicating that the future global averages will be unlike conditions experienced previously at elevation (Mann et al 2008; IPCC 2013), those elements that act on the position of the treeline are of specific interest to researchers then as they further indicate how trees could respond to future climatic conditions and the associated environmental changes.

Geologic conditions have been argued to be the foremost determinant of treeline position at in alpine environments when advance is no longer able to continue upslope (Butler et al. 2007; Harsch and Bader 2011; Holtmeier and Broll 2012). However, there exist treeline environments where physical disturbances or rock outcropping are not a limiting agent, and treeline position is presumably able to move in response to climatic changes. This is often referred to as a "climatic treeline" (Holtmeier and Broll 2007), and it has been theorized that in times of increasing temperature seedlings will respond by establishing upslope of the historical position (Vaganov 1999). However, with biotic and abiotic interactions in this zone, as with other natural ecotones, response to change proves to be more complex. There have been several factors identified that would prevent this straight-forward climate change response that was previously expected (Lloyd and Fastie 2002; Daniels and Veblen 2004; Holtmeier and Broll 2005; Malanson et al. 2007; Danby and Hik 2007; Harsch et al. 2009; Kullman and Oberg 2009; Smith et al. 2009; Bunn et al. 2011; Elliott 2011). Response to change is often mediated by the influence of regional weather patterns, local topography, and/or current site conditions.

When the entire treeline is able to establish to a higher position upslope, this has been revealed to be the better indicator of warming conditions than would the response of radial growth to trends in annual temperature and precipitation. The ability of seedlings to establish where they had not previously indicates an overall shift in favorable conditions to a higher limit. Thus, finding and recording the occurrence of advancement upslope has been a major focus of treeline research. From a meta-analysis of 
166 treeline studies that have published prior to June of 2008 , Harsch et al. (2009) found in total, $52 \%$ of sites reported an advance with only one percent reporting recession, and the remaining studies (47\%) reporting no change in the position of treeline. While the mean annual temperature increased at 111 studied sites, however, it should be noted that this was not correlated to treeline advance, rather more directly correlated was increasing temperature during winter months which allows for an extended growing period. Additionally, many articles have cited increased establishment at treeline due to warmer temperatures during the historical growing season and during an increasing number of months of the year (Elliott and Baker 2004; Danby and Hik 2007; Holtmeier and Broll 2007; Harsch et al. 2009; Kullman and Oberg 2009; Elliott 2012b). Diverging growth patterns in the past decades, though, have illustrated that this may not remain constant. Many studies (Lloyd and Fastie 2002; Daniels and Veblen 2004; Wang 2006; Danby and Hik 2007; Elliott 2011; Elliott and Cowell 2015) show that trees at treeline begin to react to the increased moisture stress due from increasing temperatures and reduced snowpack during the cool season. Daniels and Veblen (2004) found too that temperature conditions that encouraged radial growth were opposite of those conditions that were conducive to seedling establishment. Where cool and moist summer temperatures would limit growth, these conditions support the germination of seedlings and the possibility of movement of the treeline position (Daniels and Veblen 2004; Fajardo and McIntire 2012; Elliott and Cowell 2015).

Changes in prevailing climate conditions and length of the growing season will, understandably, affect tree growth on a much larger scale than will individual, local environments as climatic change affects a greater area and dictates the possibility of tree establishment. However, regional differences occurring at the landscape and slope scales are nested within the larger global view and understanding site conditions is required to understand how each interprets a changing environment. Patterns of establishment at treeline display the trend of responses to climatic conditions filtered by regional dynamics and local site conditions (Holtmeier and Broll 2007; Holtmeier and Broll 2012; Bourgeron et al. 2015) as has been seen with tree growth. Studies across mountain ranges within Alaska (Lloyd and Fastie 2002) and in the Andes of Chile and Argentina (Daniels and Veblen 2004) found correlations at first between treeline growth and 
annual temperature. However, with increasing temperature, favorable tree growth continued in mesic sites but was negatively correlated with sites located in xeric locations. They attributed this inverse relationship to a dependence on moisture availability, where the dry environments under moisture stress increased evapotranspiration and decreased moisture availability. This alleviated warming temperature conditions for a time, but there was a threshold where the ability of the ecotone to benefit from warming temperatures was undercut by the lack of necessary moisture for continued growth. Mesic sites were not limited by moisture availability, and thus continued favorable growth during this period.

Temperatures increased after the 1970's in the Bighorn Mountains (Elliott 2012b), where upslope advancement occurred along with an increase in density to the elevation of the outpost tree where previously they had been able to grow only in the shelter of topographical features. Elliott found that this was indicative of a broad-scale, bioclimatic threshold being crossed, where the warming temperatures of the late $20^{\text {th }}$ century have surpassed a limit that allowed for rapid upslope advancement and density increase at an unprecedented rate compared to the sampled 210-year history (Elliott 2012b). This allowed for an alternate phase of stability in the treeline population and a change in the spatial patterns of establishment. While the shift was largely initiated by climatic change, local site conditions allowed for an immediate regeneration response to take place.

In the northern hemisphere, the southern facing aspect receives more direct sunlight on average throughout the day affecting surface temperature and moisture available to vegetation. The northern facing aspect is generally cooler and able to retain more moisture due to shielding from the lower angle of the sun. Some studies on the effect of aspect on treeline growth patterns reveal that northern slopes have increased in density but have not advanced upslope during times of warming climatic conditions (Danby and Hik 2007; Harsch et al. 2009). While other research has shown individuals on both northern and southern slope aspects were able to establish upslope during warming climatic conditions, with differing spatial patterns. In the southern Rocky Mountains of Colorado and New Mexico, Elliott \& Kipfmueller (2010) found that random establishment on northern-facing slopes after 1950 indicate the increased susceptibility of treeline advance to warming temperatures. Southern aspects also showed 
advancement but in a clustered spatial pattern from stress due to relatively thin soils and low moistureholding capacity. These conditions encourage clustered establishment, which only would have increased as temperatures rose. The existence of a diffuse treeline, may itself, indicate conditions more favorable for advance when compared to a clustered growth pattern which would rely on neighboring vegetation for sheltered growing conditions (Harsch et al. 2009; Elliott 2011).

Radial tree growth may not be affected in the same manner as establishment, as growth is often responsive to a local limiting agent. Studies have shown that the primary limiting agent can change depending on location within the site itself (Bunn et al. 2011; Bourgeron et al. 2015) and along the elevational gradient leading to treeline (Liang et al. 2014; Salzer et al. 2014). At the furthest extent of treeline, growth is prohibited when a sufficient growing temperature is never reached; but further downslope where temperature remains consistent enough to support growth, it has been shown that these areas can be limited by insufficient moisture (Salzer et al. 2014). Further, the soil temperature that Körner (2004) referred to as the average limit of treeline establishment does not fully describe the behavior of radial growth when air temperature remains sufficient, which may be found equally across opposing aspects (Wang et al. 2013). I hypothesize that due to the known differences in moisture retention on the northern versus southern slope, there will be a significant gain in basal area on both sites due to adequate growing season temperature; however, since the southern site displays a tendency to establish only in areas of topographical sheltering this will result in lessened growth due to solar exposure and a rising annual temperature.

\section{STUDY AREA}

The Bighorn Mountains are located in north central Wyoming, oriented north to south, with its northern terminus near the border of Montana. Due to the range's location on the eastern side of the Rocky Mountains, the Bighorns do not receive much precipitation from continental westerlies, as most of this moisture is depleted from crossing the main spine of the Rockies (Despain, 1973). Rather, continental air masses from the north and northeast often come through a gap between the Pryor and Beartooth ranges 
Bighorn Mountains Temperature

(a.) Average Maximum

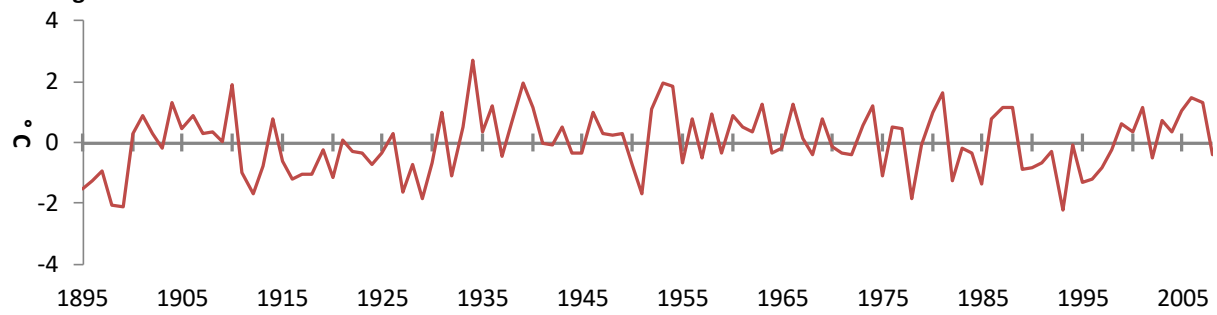

(b.) Mean Annual

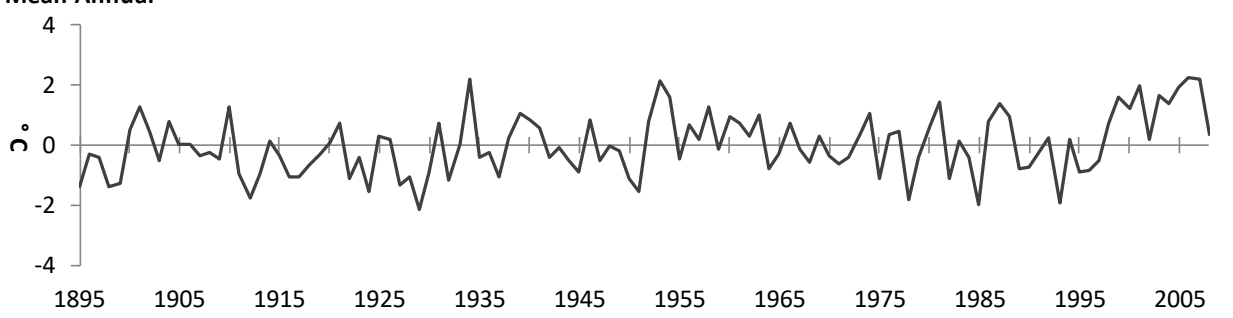

(c.) Average Minimum

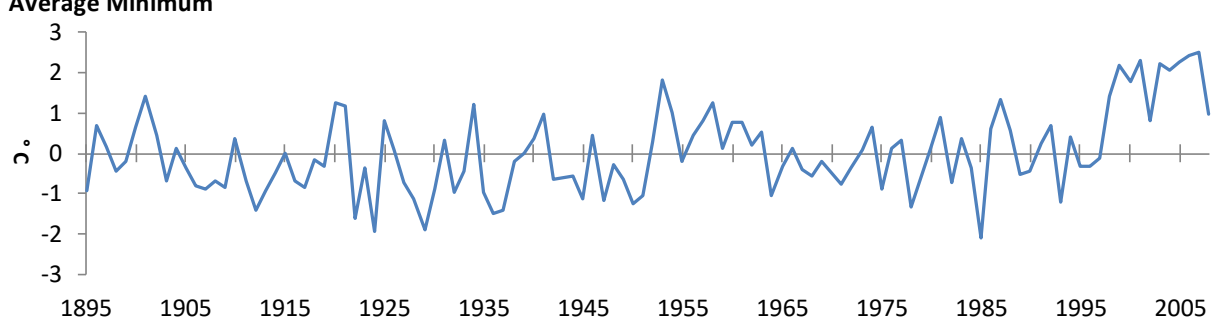

Bighorn Mountains Precipitation

(d.) Total Annual

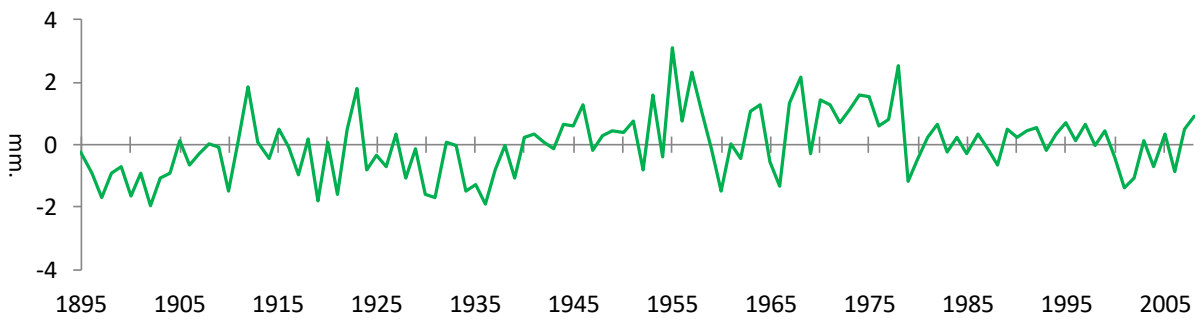

(e.) Cool Season (November - May)

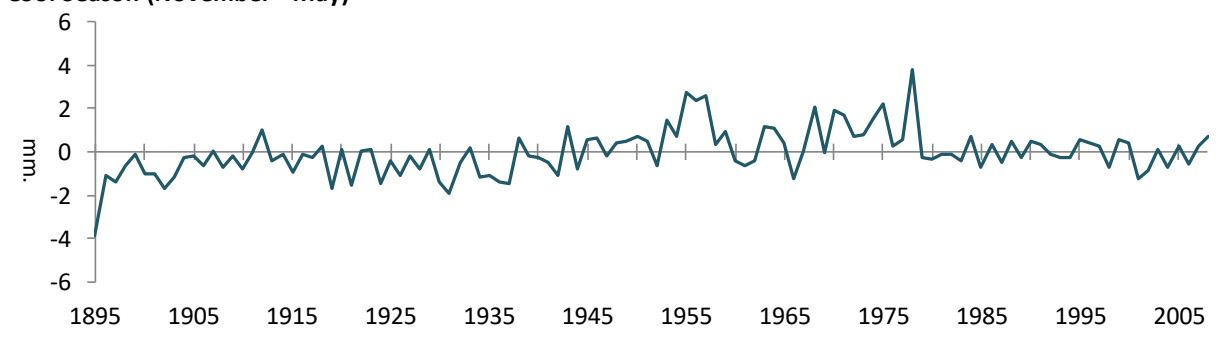

Figure 1: Bighorn Mountain Precipitaiton: Departure from mean $\left({ }^{\circ} \mathrm{C}\right)$ during the study period (1895-2008) of (a.) average maximum, (b.) mean annual, and (c.) average minimum temperature. Bighorn Mountain Precipitation: Depature from mean ( $\mathrm{mm}$.) during the study period $(1895-2008)$ of (d.) average annual precipitation and (e.) the amount of precipitation received as snowpack during the cool season months (November - May). Data obtained from PRISM data models for the Bighorn Mountains near the study site (PRISM, 2010). 
(Mitchell 1976). The northwestern and northeastern side of the Bighorns receives the majority of this moisture with the western slope the driest and a rain shadow extending to the southeast. From 1970 to 2008, the Bighorn range received an average of $76.2 \mathrm{~cm}$ of precipitation per year (fig. 1d), mainly contributing to snowpack during the months of November through May. Maximum, minimum, and mean temperatures have increased approximately $2^{\circ} \mathrm{C}$ since 1900 (fig. 1a, 1b, and 1c) (PRISM, 2010).

The upper treeline ecotone of Bruce Mountain contains the following tree species: Abies lasiocarpa (Subalpine Fir), Picea engelmannii (Engelmann Spruce), Pinus albicaulis (Whitebark Pine), and Pinus contorta (Lodgepole Pine). Studies reveal that the species Pinus albicaulis and Pinus contorta are largely tolerant of rocky and infertile soil as well as high solar receipt, while Picea engelmannii and Pinus albicaulis thrive better in shade (Burns and Honkala 1990; Uchytil 1991); however, Pinus albicaulis is the only species with a high drought tolerance at an early age due to rapidly growing deep roots (Fryer 2002). All others are highly intolerant of drought due to shallow root growth. Pinus contorta is more commonly found on granitic soils (Burns and Honkala 1990) which would have a low moisture capacity while Picea engelmannii and Abies lasiocarpa generally occupy sedimentary soils which are more defined and have a greater potential to store moisture (Burns and Honkala 1990; Uchytil 1991). In open conditions seedling production begins for Pinus albicaulis when the tree is 1.2 to $1.5 \mathrm{~m}$ ( 4 to $5 \mathrm{ft}$ ) tall and generally 20 years old (Fryer 2002), Pinus contorta can begin production as early as 5-10 years old (Burns and Honkala 1990), Picea engelmannii can produce seeds when 15 to 40 years old and 1.2 to $1.5 \mathrm{~m}$ ( 4 to $5 \mathrm{ft}$ ) tall, while Pinus albicaulis produces at 20 to 30 years of age on favorable sites (Fryer 2002).

\section{METHODOLOGY}

\section{Field Methods}

The alpine treeline ecotone represents the transition zone between the treeline, the elevational limit of upright tree growth, and the timberline, the upper elevational limit of the closed canopy forest (Malanson 2007). The individuals sampled for this study were those that extend downslope from the outpost tree through the treeline ecotone and $40 \mathrm{~m}$ below the timberline (BTL) and were above the timberline. The 
outpost tree (term from Paulsen et al. 2000) refers to the furthest upright tree greater than $1.2 \mathrm{~cm}$ diameter at ground level ( $\mathrm{dgl})$ within the treeline ecotone. This research utilized only those saplings that establish above the timberline (ATL) and within $20 \mathrm{~m}$ of either side of the transect and all trees within $10 \mathrm{~m}$ of either side of the same transect.

The samples for this research were collected at several sites during 2008 in the Bighorn Mountains for related age structure research (Elliott 2012b) in order to identify threshold changes in treeline establishment throughout the $20^{\text {th }}$ century due to changing climatic conditions, over varying scales. All of the sites were selected a priori using aerial photographs to ensure suitability for the purposes of this research. These sites needed to be free of geological constraints such as a recent disturbance or geological features that would have prevented upslope expansion in order to focus on the response of tree growth and establishment to changing climatic conditions.

Site characteristics were documented in each location to describe the current condition of individual trees and those variables thought to influence tree growth. These included: elevation and GPS coordinates of the outpost tree, slope aspect, and slope steepness $\left({ }^{\circ}\right)$. Tree characteristics collected were: species, dbh, coring height, and whether the individual established in the shelter of a topographic feature (boulder) as well as the $x$ and $y$ coordinates to the nearest $0.1 \mathrm{~m}$. (Elliott 2012b). At each location, sites were sampled from a location on the southern ( $135^{\circ}$ to $225^{\circ}$ azimuth) and northern ( $315^{\circ}$ to $45^{\circ}$ azimuth) aspects. Two increment cores were taken at $30 \mathrm{~cm}$ above the ground from all living trees $(\geq 5 \mathrm{~cm} \mathrm{dbh}, \geq 9 \mathrm{~cm}$ dgl) along the transect. Every sapling within the transect was harvested at ground level and 10-15 were sectioned at $30 \mathrm{~cm}$ to determine a correction factor for age-at-coring height. Seedlings $(<1.2 \mathrm{~cm}$ dgl) were inventoried by species throughout the entire transect at both sites. (Elliott 2012b).

\section{Lab Methods}

Cores and cross sections collected were processed using standard dendrochronological procedures (Stokes and Smiley 1996), by mounting and sanding the length of the core and face of a cross-section with increasingly finer sandpaper to produce a smooth surface that could be imaged by a flatbed computer 
scanner. The samples were then scanned and measured using WinDENDRO software (Regent Instruments Inc., Quebec, QC, Canada). Using this program, the samples total annual growth was measured to the nearest $0.001 \mathrm{~mm}$ and archived. The annual measurements at each site were then correlated by skeleton plotting to match rings of significantly reduced growth (marker rings) and verified using the program COFECHA (Holmes 1983) in order to create a cross-dated record for all trees sampled. Any suspicious growth was visually checked for false or missing rings under a microscope.

For those cores where the pith was not visible, pith estimators were used to geometrically determine the number of years to the date of establishment. As the radial growth was used to compare rate of growth to the occurrence of establishment, the estimated period of missed rings were added to the growth the properly adjust the growth measurements to the population. This would ensure that when trends in growing patterns were compared to the number of individuals found at the site, they would be accurate to which actually existed rather than assuming the last year of growth found on the core would be the date of establishment.

\section{Data Analyses}

Due to the short span of years since the surge in upslope advancement, detrending all cores proves difficult as accounting for longer climatic trends and would be cumbersome to detect and remove. In addition, the practice of removing the geometric trend of tree growth due to an increasing circumference were often atypical and annual width increased with age which may be due to sheltering or a characteristic of the spatial pattern of establishment. Thus, once the record of annual measurements was cross-dated to the other sampled cores to synchronize growth years, annual ring width was used to calculate a Basal Area Increment or BAI using the following formula:

$$
B A I=\pi\left(R_{n}^{2}-R_{n-1}^{2}\right)
$$

Where $R$ is the radius of the tree and $n$ is the current year of ring formation. This increment is a measure of primary production of each measured stem on the site that projects the amount of annual growth in a complete circle around the base to find the area $\left(\mathrm{cm}^{2}\right)$ of woody growth that each year adds. This allowed 
for a comparison of growth of each stem and to recreate stem diameter annually. By reconstructing annual stem diameter, it is possible to test the weighted influence of stem size on neighboring growth during analysis as well as showing the area of the plot occupied by tree stems.

The rates of production as BAI on the north site and on the south site were plotted separately to allow for a visual comparison of growth. On each site, the annual BAI values $\left(\mathrm{cm}^{2}\right)$ of each tree that had established were averaged to all other values that existed that year to provide the mean annual value of growth. The number of samples used to calculate an average would increase with age as younger trees would occur later in the record. These average values of each site could then be compared using a Pearson correlation to find if rates were significantly similar on the opposing aspects. For additional comparison, samples limited to only those trees which established after 1970 were compared with the same test for both sites to find how the rates of production changed following the regime shift upslope.

Then, the growth of each tree core as represented by BAI $\left(\mathrm{cm}^{2}\right)$ was averaged across five-year age classes beginning with the first instances of upslope advancement beginning in 1970 to allow for periodic comparison of the changing patterns of establishment. The population for the north site $(n=34)$ and the south site $(n=27)$ were classified into eight age classes defined as 1970 (1970-1974), 1975 (1975-1979), 1980 (1980-1984), 1985 (1985-1989), 1990 (1990-1994), 1995 (1995-1999), 2000 (2000-2004), and 2005 (2005-2008) in which 2008 was the year of sampling. The two trees that existed prior to 1970 on the south site (BMS 16B and BMS 18) were included in the analysis as their location and size would be critical to include when discussing spatial pattern change, but no age classes were created for years prior to 1970 due to the small sample $(n=2)$. Growth and basal area during these five years were averaged to find the mean to allow for comparison across all samples on both sites. The date of establishment of each tree and the location of establishment (measured in 0.1 meters from the location of the outpost tree) was used to determine if the subsequent establishment over time was significantly clustered or dispersed.

To do this, the samples were processed through the "ads" package (Pelissier and Goreaud 2015) in the statistical computing program R (R Development Core Team 2009). The total data set of available samples 
on the north and south sites were refined during each age class to represent only those established during or prior to that period. The purpose of this was to determine if the spatial pattern of establishment through time was increasingly clustered, dispersed, random, or changed through the study period. To identify this, the location of the samples $(x, y)$ were processed to identify the amount of clustering beyond a specified distance, to identify the distance at which the likelihood of neighboring stems were found, and if the tree size or species influenced the pattern of establishment through subsequent age classes.

Using Monte Carlo Simulation ( $n=999 ;$ Diggle 1983) at each distance of $r$ (1-20 meters) placed randomly across the site, the program determines the observed number for trees at a set distance from the point using Ripley's K $(K(r))$ statistic (Ripley 1977). When the observed numbers of stems is greater or less than the confidence envelope for randomly located stems $(P<0.01)$, they are determined to be significantly clustered or dispersed (respectively). This is described in the formula:

$$
K(r)=N(r) / \lambda
$$

where $\lambda$ is the mean number of points per unit area or intensity and $N(r)$ is the observed number of neighbors within distance $r$ which is the increment of the test. Since the expected value of complete spatial random (or CSR) of Ripley's K is equal to $\pi r^{2}$, this was then transformed as a $L(r$ ) function (Besag, 1977), where the observations are easier to visually assess against the expected value (CSR=0).

$$
L(r)=\sqrt{\pi^{-1} K(r)}-r
$$

Then, using the pair density function $(g(r))$ and a same number of Monte Carlo Simulations $(n=999)$, it can be determined the average distance from randomly placed location to a nearest neighbor at each tested distance (Stoyan, Kendall, \& Mecke 1987). Described as:

$$
g(r)=\frac{d K(r)}{d r} / 2 \pi r
$$

where CSR=1.The pair density function differs from Ripley's K in that the number of observations is taken in a ring at that specific distance out from the point whereas Ripley's $\mathrm{K}$ is cumulative determining the spatial arrangement from or less than that measured distance. 
In addition, using univariate marked pattern analysis (Goreaud 2000), a quantitative component was added to each sample to represent the basal area of each stem during each of the age classes. With this, it could be determined at each of the distances chosen, whether or not the size was a determinant on the growth of neighboring individuals. Those found to be outside of the confidence envelope for Monte Carlo simulations of random placement $(P<0.01)$ had a positive or negative influence on neighboring growth as a value range from -1 to 1 . This is written:

$$
\operatorname{Km}(r)=\operatorname{Cov}\left(X_{i} ; X_{j}\right) k_{i j}=\operatorname{Var}(X) N(r)
$$

where $X$ is a random variable defining the mark (in this case stem area) at points $i$ and $j$ and $N(r)$ is the observed number of pairs of neighbors within each distance of $r$. In which,

$$
N(r)=\sum_{i=1}^{N} \sum_{j \neq 1}^{N} k_{i j} /_{N}
$$

and $k_{i j}=0$ if $d(i j)>r$ or $k_{i j}=2 \pi r / P_{i j}$ with the perimeter $(P)$ of the circle centered on $i$ passing through $j$, which is inside the sampling window. When $d(i j) \leq r, k_{i j}=1$ if point $i$ is closer than $r$ to the border of the site boundary and $k_{i j}>1$ otherwise, to account for the edge effect of the site.

Then, using a transformation of multivariate marked pattern analysis $\left(L_{12}(r)\right)$, the qualitative component of species was added to the location to find if the species had an impact on the spatial pattern of establishment (Duncan 1991). This test checked to see if each species of the sampled trees on the site was a determinant on if the location was clustered or dispersed when compared to the expected level of random placement. In this statistic, only the sampled trees were included to show the distribution within the site. This is based off the bivariate function of:

$$
N_{12}(r)=\sum_{i=1}^{N_{1}} \sum_{j=1}^{N_{2}} k_{i j} / N_{1}
$$

where $N_{1}$ and $N_{2}$ are the number of type 1 and type 2 points of the pattern. The $K_{12}(r)$ function (Lotwick and Silverman, 1982) used in this study computes an array for each mark (species) against all other species grouped together in a multivariate point pattern. This function is described as: 


$$
\begin{gathered}
K_{12}(r)=N_{12}(r) / \lambda_{2} \text { where } \lambda_{2}=N_{2} / A \text { and } A \text { is the site area } \\
L_{12}(r)=\sqrt{K_{12}(r) / \pi}-r
\end{gathered}
$$

where $\mathrm{CSR}=0$. On each site, there were three species types found. On the north site, the species found were: Abies lasiocarpa, Picea engelmannii, and Pinus contorta; while on the south site were: Abies lasiocarpa, Pinus albicaulis, and Pinus contorta.

\section{RESULTS}

Average annual growth, represented as Basal Area Index (BAI), of all trees on the site during each year yields a low correlation (0.36) from a Pearson correlation as this includes two samples which established approximately sixty years prior to the mass upslope advancement in 1970 (fig 3 \& 4). This resulted in the samples having a larger base and producing a much greater area of annual growth in comparison to those just beginning to begin producing annual rings. If these are removed for only this test, what is left is the average production limited to only those that established after 1970 (fig. 3), and the growth is highly correlated (0.99) from the north to the south. The average annual growth (approximately $2 \mathrm{~cm}^{2}$ during the year of sampling) is slightly greater on the southern site, but the rate at which they have produced is nearly identical. When separated by species and elevation, this same high correlation remains throughout all classes (fig. 5 \& 6; Table 2). The lowest correlation comes from a comparison between the lowest elevational increments of shade tolerant species on either aspect with the highest increment of species that are intolerant. There are slight differences between the lowest and highest elevational increments of each species, though these still remain highly correlated.

Further, at the time of sampling the tree population was largely open grown, or unsheltered, on the northern site (32:2) and largely sheltered on the southern site (24:3). Seedlings inventoried on the northern site continued with unsheltered establishment with an additional 5 seedlings growing in the open, while on the southern site an additional 3 seedling were found in shelter and 5 seedlings found growing open near the border of the timberline. This shows that after 1970 the conditions that affected 


\section{Bruce Mountain North}

Sheltered

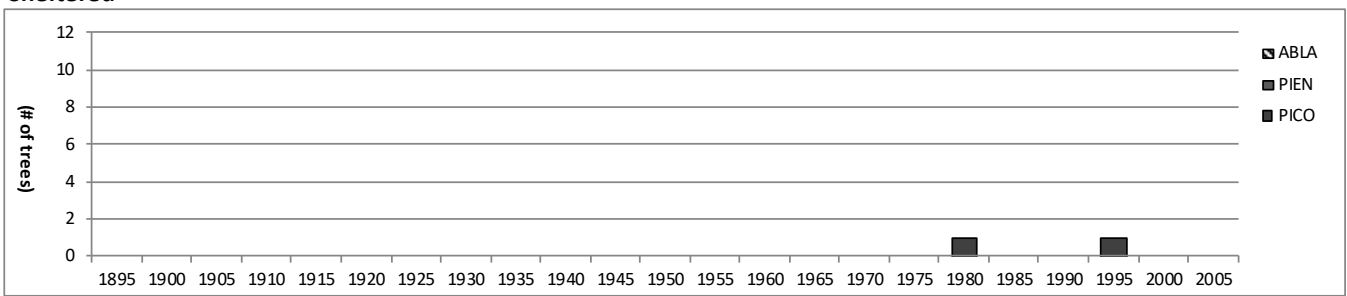

Non-sheltered

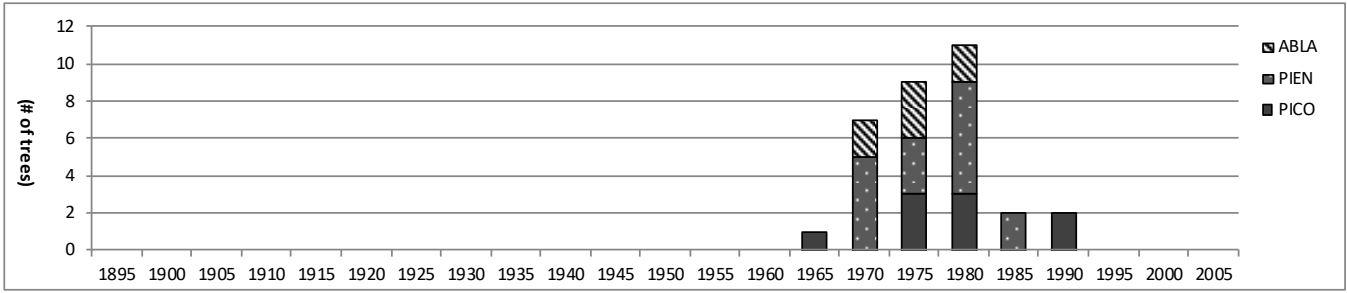

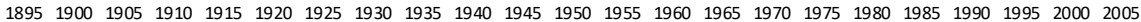

Seedlings

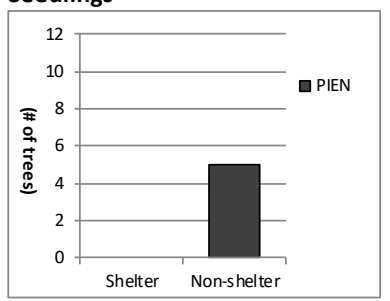

\section{Bruce Mountain South}

\section{Sheltered}

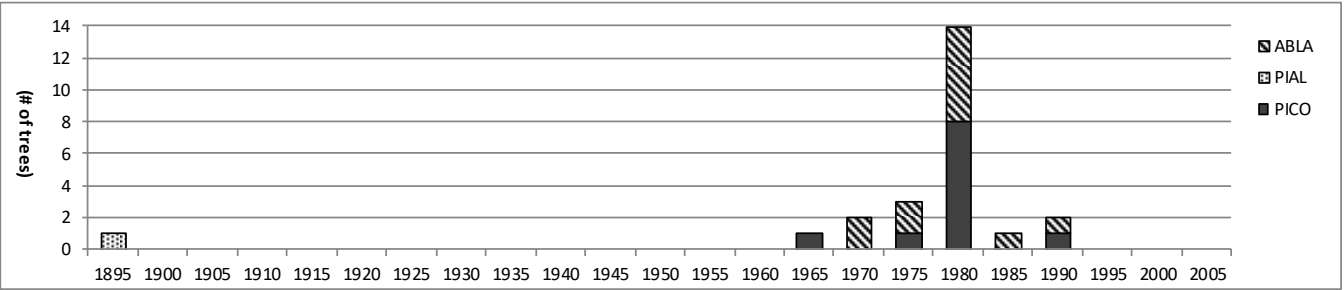

\section{Non-sheltered}
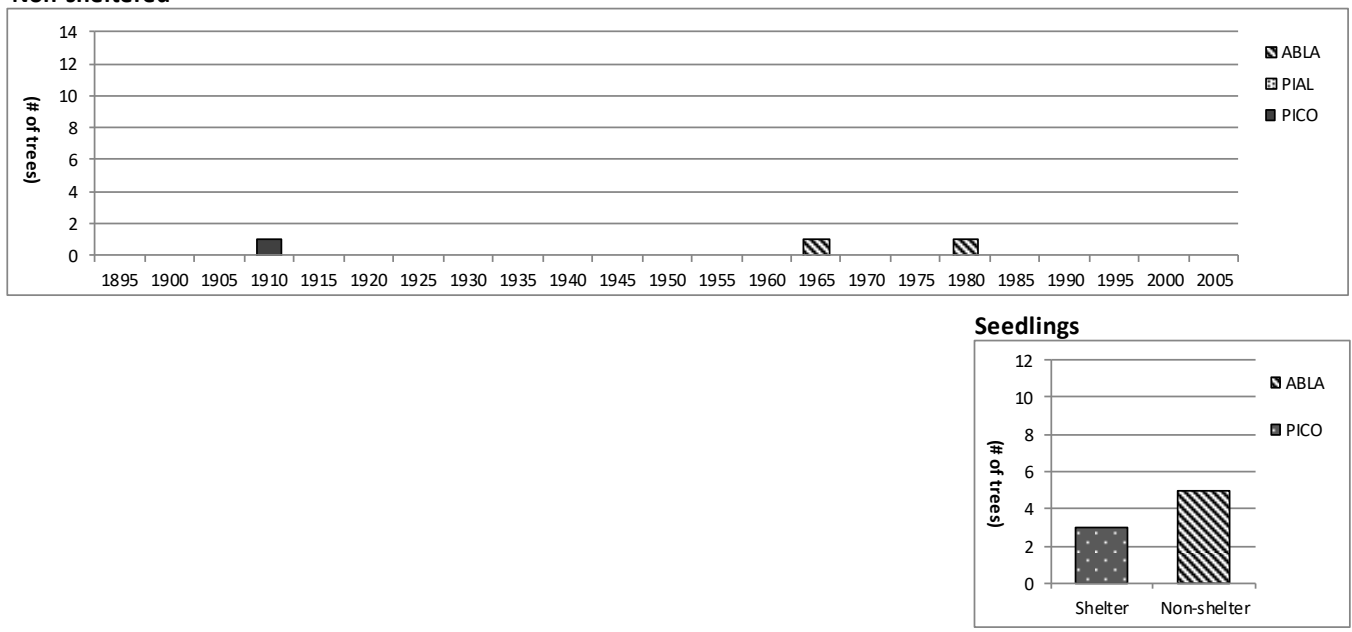

Figure 2: Displays the number of samples collected on Bruce Mountain North and Bruce Mountain South that established during each age class. The samples were separated into charts by the mechanism of facilitation (i.e. establish in the shelter of boulders or in the open) for each site and then divided within each by the species of the sample collected. Tree species identified by standard four-letter code: Abies Lasiocarpa (ABLA), Picea Engelmannii (PIEN). Pinus Albicaulis (PIAL), and Pinus contorta (PICO). Seedlings were inventoried by species throughout both sites but not dated. 


\section{Bruce Mountain North}

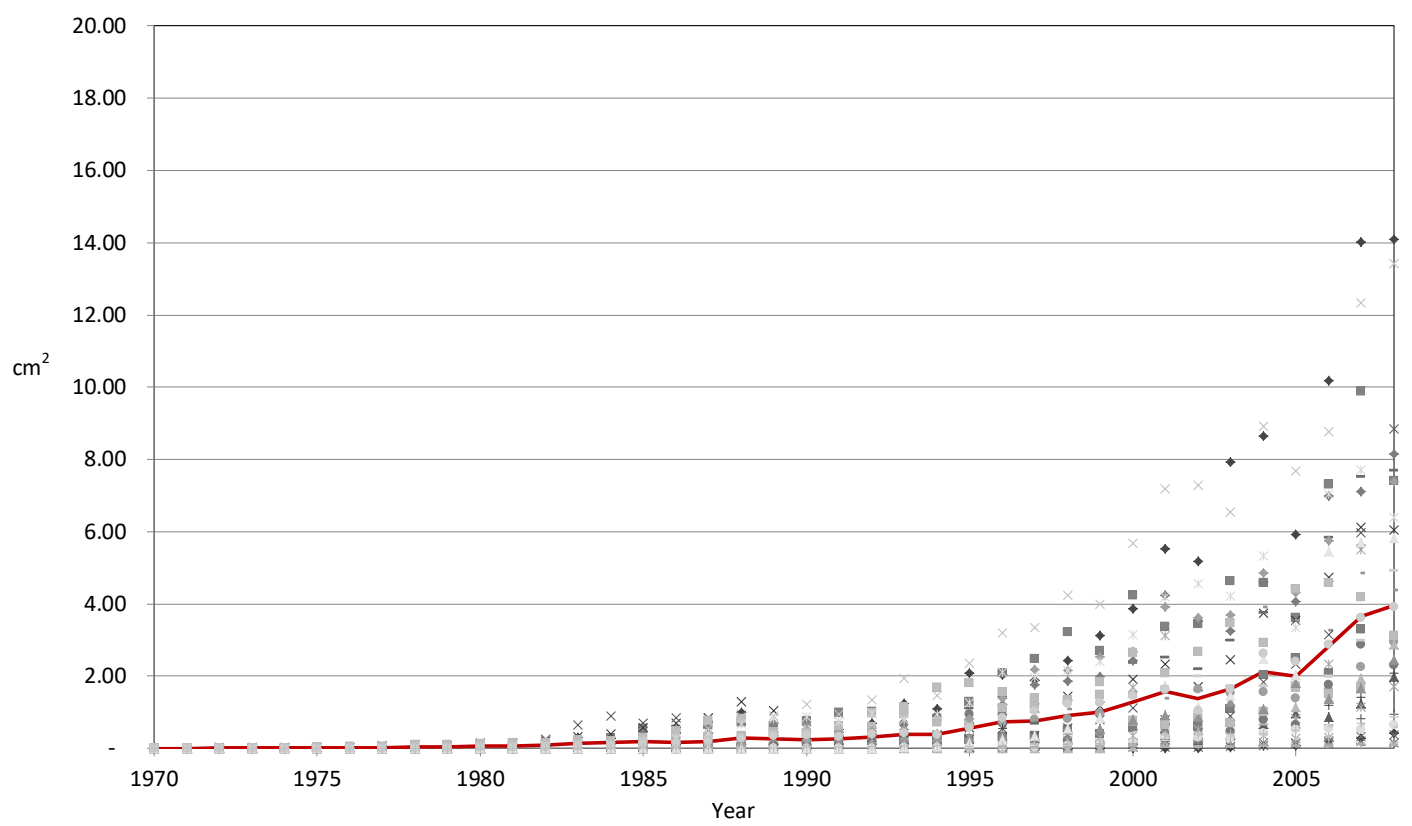

Bruce Mountain South (excludes samples established prior to 1970)

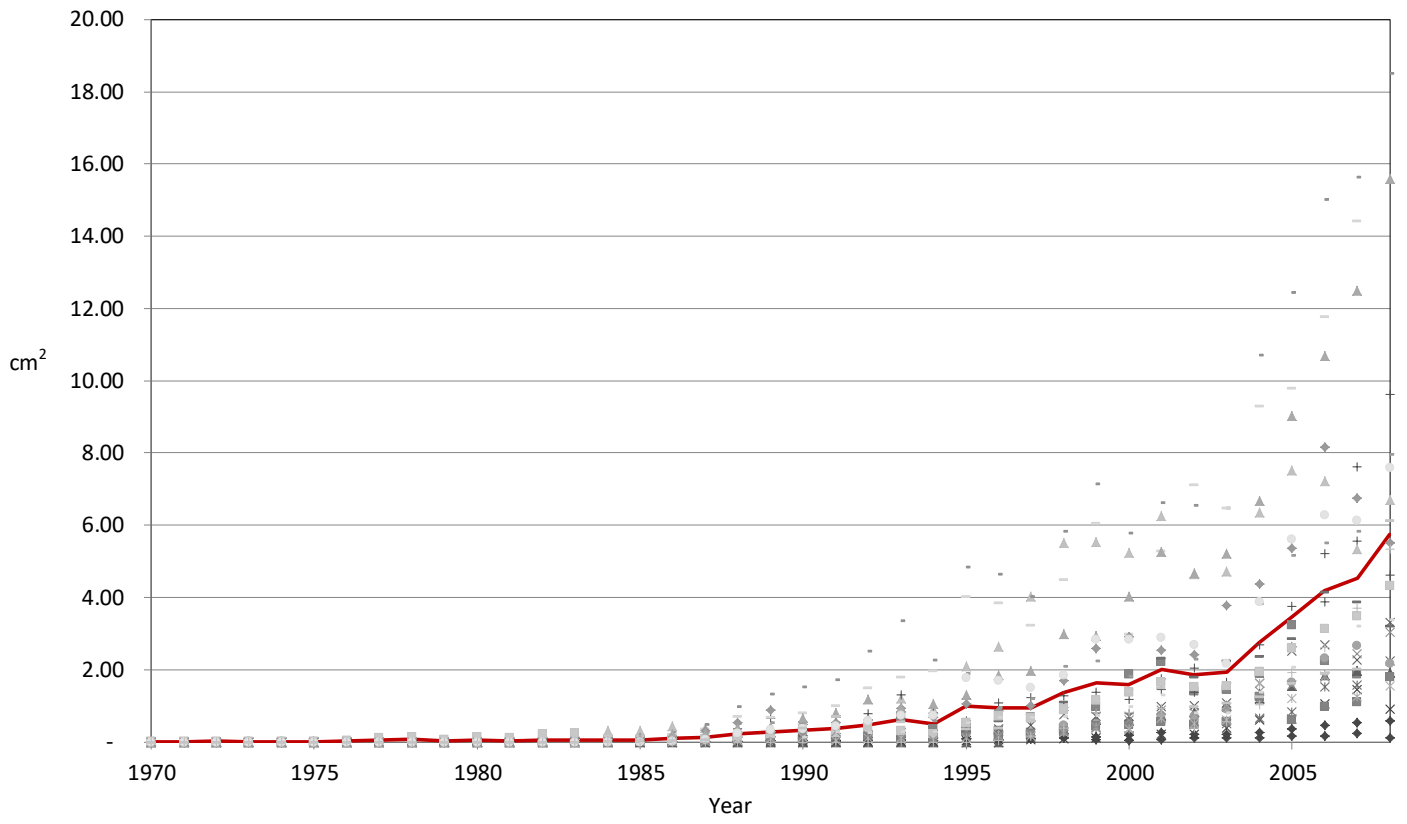

Figure 3: Annual Basal Area Index (BAI) values $\left(\mathrm{cm}^{2}\right)$ of each tree that had established on the Bruce Mountain North (BMN) and Bruce Mountain South (BMS) study sites. These samples were averaged to all other values that existed that year to provide the mean value of growth. The number of samples to average would increase with age as younger trees would occur later in the record. By removing the two trees on the southern site that established prior to 1970, the trend in BAI production is nearly identical to the northern site. 
Table 1: Study Site Characteristics for Bruce Mountain; Bighorn Mountain Range, Wyoming

\begin{tabular}{|c|c|c|c|c|c|c|c|c|}
\hline Site Name & Site Code & $\begin{array}{l}\text { Site Coordinates } \\
\text { (UTM - E, N) }\end{array}$ & $\begin{array}{l}\text { Elevation } \\
\text { Range (m) }\end{array}$ & Aspect $\left({ }^{\circ}\right)$ & Slope $\left({ }^{\circ}\right)$ & $\begin{array}{c}\text { Total } \\
\text { Sampled } \\
\text { Trees (n) }\end{array}$ & $\begin{array}{c}\text { Sheltered: } \\
\text { Non-sheltered } \\
\text { trees }(\mathrm{n})\end{array}$ & $\begin{array}{c}\text { Total } \\
\text { Seedlings } \\
\text { (n) }\end{array}$ \\
\hline Bruce Mountain - North & BMN & 304812,4944518 & 2999-2909 & 10 & 17 & 34 & $2: 32$ & 5 \\
\hline Bruce Mountain - South & BMS & 304972,4943817 & $3007-2844$ & 210 & 19 & 27 & $24: 3$ & 8 \\
\hline
\end{tabular}

\section{Bruce Mountain South (Total)}

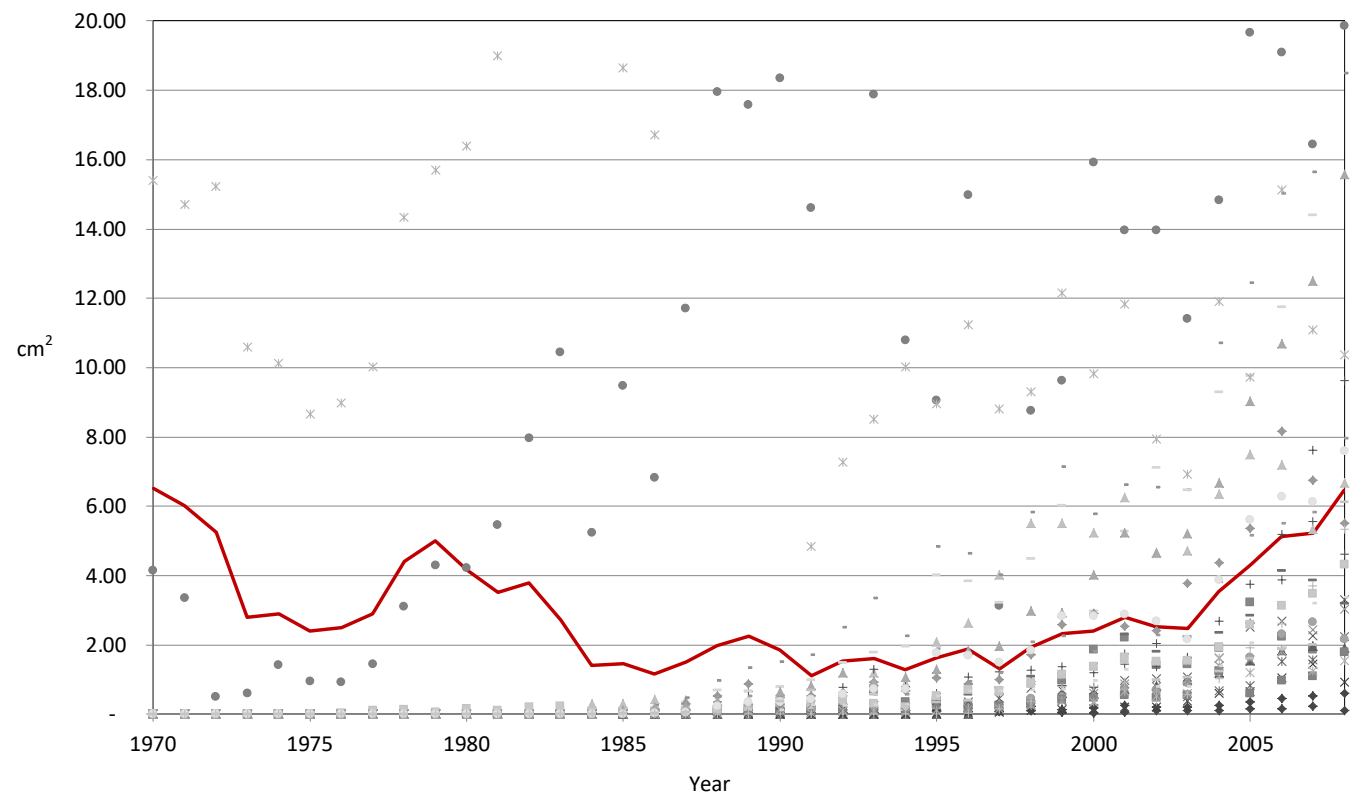

Figure 4: Annual Basal Area Index (BAI) values $\left(\mathrm{cm}^{2}\right)$ of each tree that had established on the Bruce Mountain North (BMN) and Bruce Mountain South (BMS) study sites. These samples were averaged to all other values that existed that year to provide the mean value of growth. The number of samples to average would increase with age as younger trees would occur later in the record. The two trees that established prior to 1970 had a larger base and produced at a higher rate during the study period. 

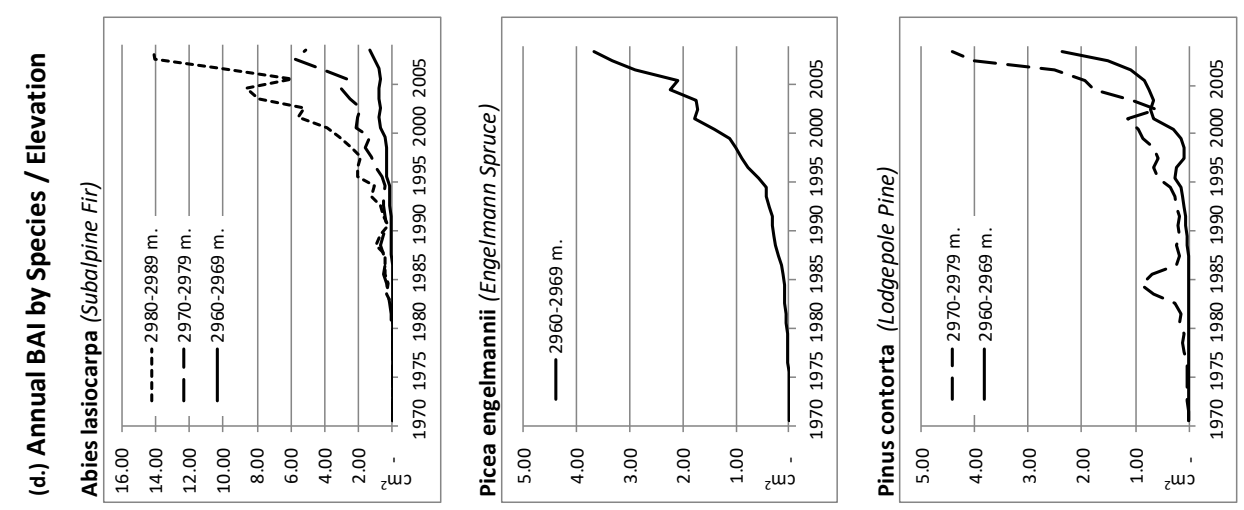

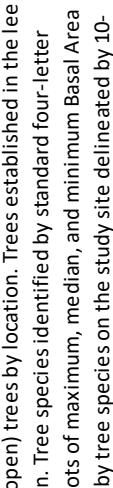

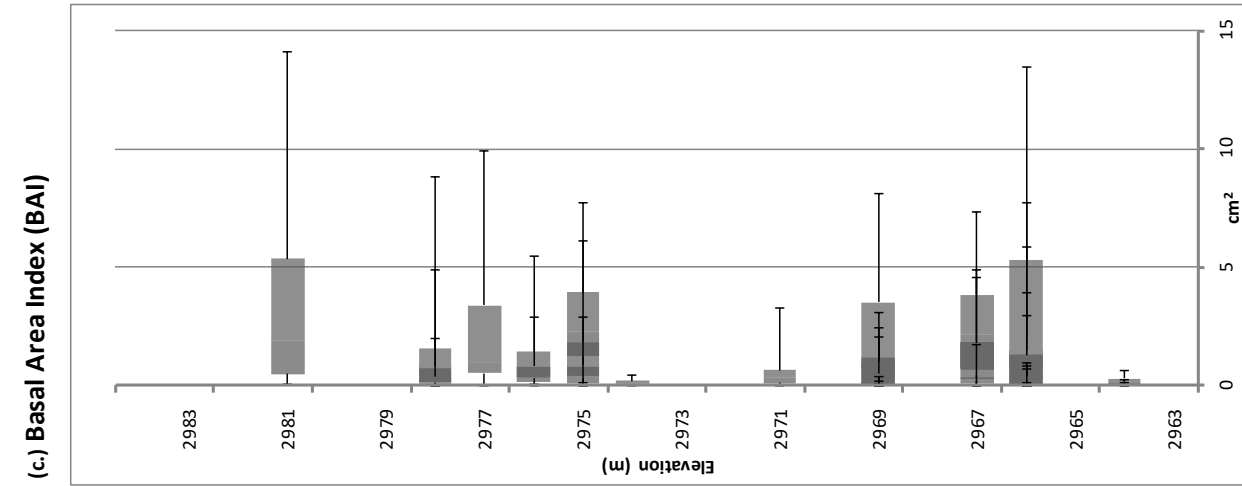

要

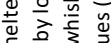

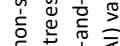

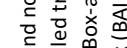

ह ट

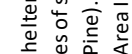

此造

है

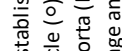

ब.

离芯空

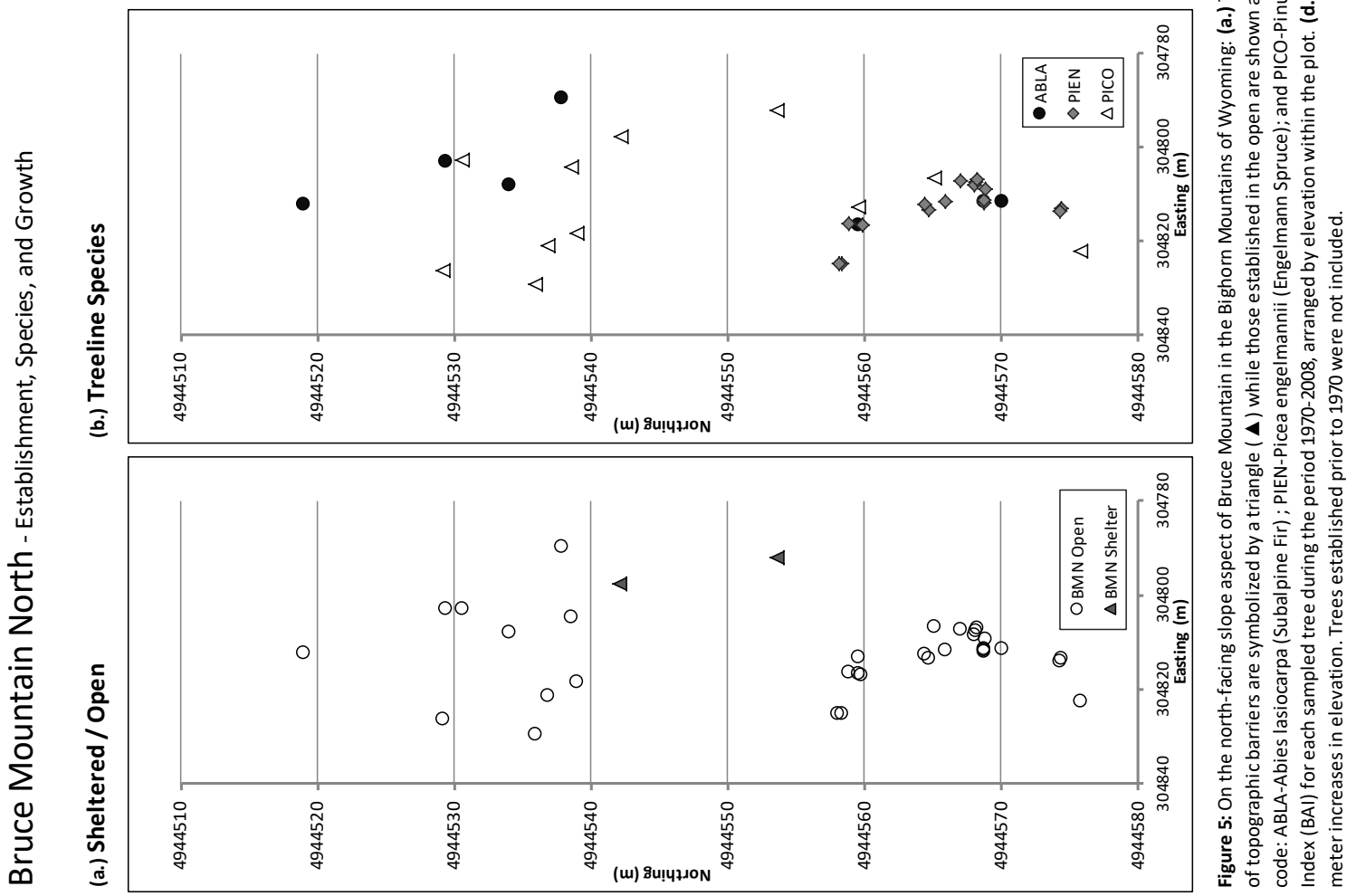



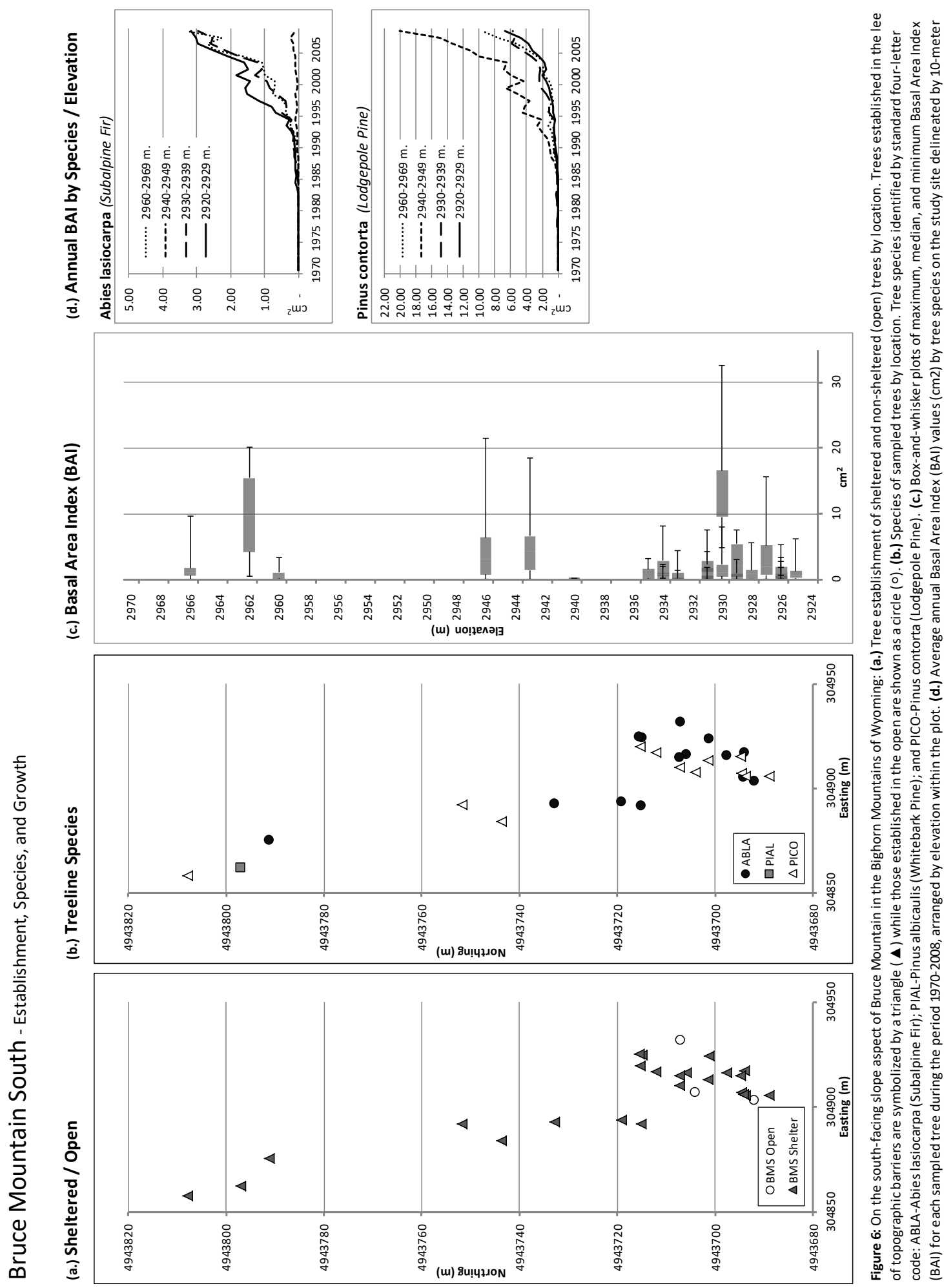
the opposing aspects created a need for a clustered spatial pattern at both sites which came about under differing mechanisms, but resulted in very similar rates of growth. The subsequent tests performed established the changing degrees of spatial arrangement and a comparison of the endogenic factors that comprised the makeup of the sample population.

Spatial pattern analysis determines the establishment pattern during each age class by recording the number of observed trees found within a test distance of a random point placed within the plot area. For each test, simulations were run at 1 meter increments up to 20 meters from the random point. This distance was chosen as it was less than half the distance of the shortest side of both sites and run with the same test increments throughout each test for comparison. Establishment was minimal during the earliest age classes and resulted in a sparse pattern across both sites. In order to obtain a significant number of samples ( $n>10)$, results could only be returned following the 1975 age class on the northern site and the 1980 class of the southern site. Due to the intense establishment during these age classes on both sites (fig. 2), it was found that once upslope advance had occurred, the pattern of establishment only increased in observations rather than fluctuating between clustered or random. In summary, figure 7 (a, b, \& c) displays the spatial structure returned from each test during the final age class (2005) with a detail of each age class provided in the Appendix.

The first test determined whether the pattern of establishment over time developed randomly, in a dispersed pattern, or in a clustered pattern. The test, the $L(r)$ transformation of Ripley's K (fig. 7a), determines the likelihood of encountering a neighboring tree within a certain distance from a random point within the plot area. Since complete spatial random (CSR) is equal to zero in this transformation, a positive value indicates the pattern is more clustered than would happen randomly and a negative value indicates more dispersed than would happen randomly given that the value is greater (or less) than the confidence envelope created by the Monte Carlo simulations. During the 1975 age class, the pattern becomes significantly clustered within 13 meters but random beyond. This level of significant clustering extends to the greatest test distance in 1980 and 1985, and with the largest period of establishment during the 1970-1980 classes on the northern site, the pattern of clustered establishment goes largely 

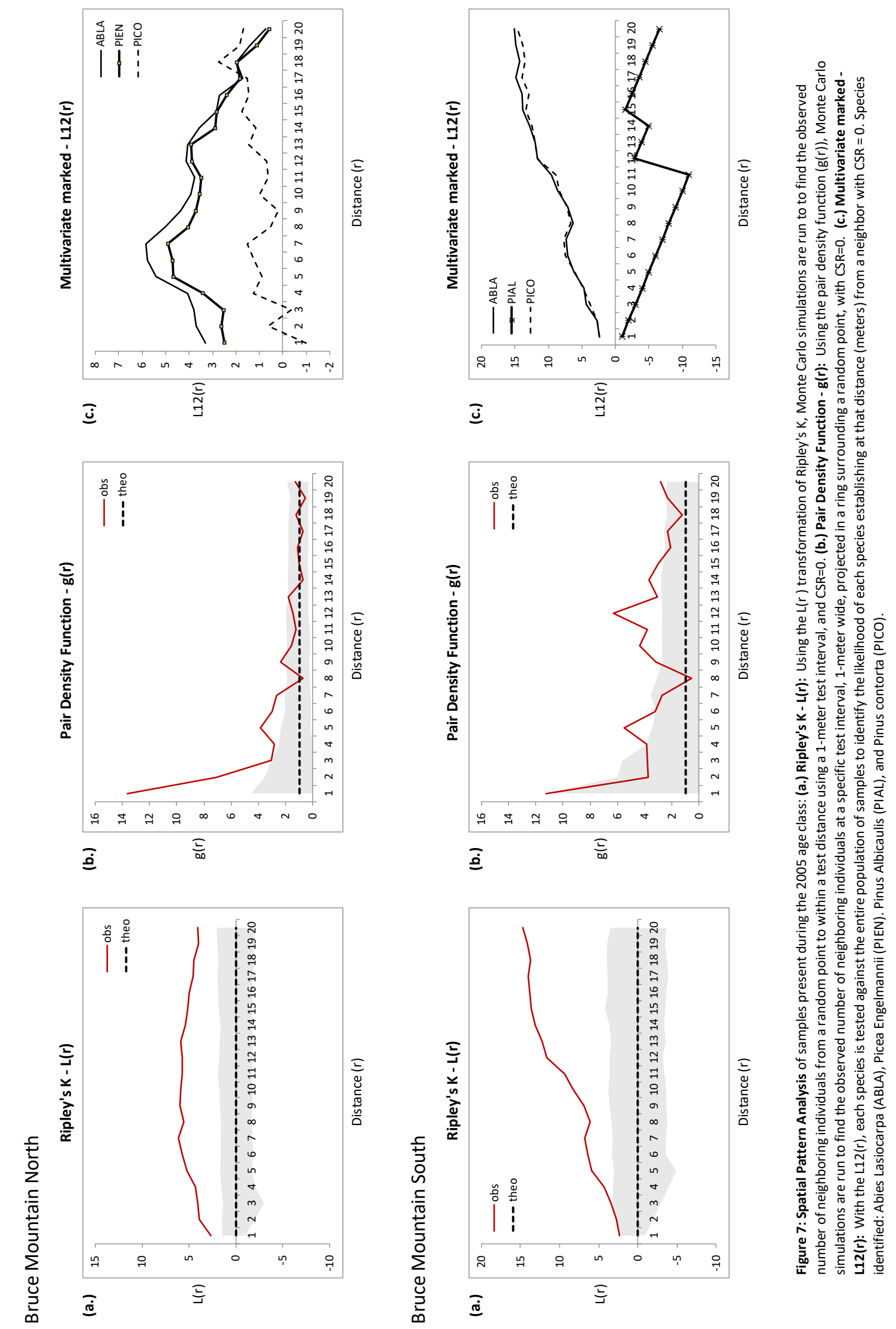
unchanged from 1985 through to the time of sampling. On the southern site, the timing of establishment occurs largely during the 1980 class where it is clustered beyond the 10 meter increment. Through the remaining age classes and the addition of three more individuals, the degree of clustering occurs closer to the smallest test increments or the center of the random point, but it is never significantly clustered at less than 3 meters during the test period. This most likely means that the position of all individuals established with enough distance between each other that they were able to survive independently or under the influence of some other factor than sheltering by neighboring trees.

Using the pair density function $g(r)$ on the same age classes (fig. 7b), the pattern of establishment is more descriptive as to the exact increment where the neighboring trees are found because it tests only the measure between each distance and the preceding test increment. On the northern site and throughout the age classes, as more trees established the likelihood of having a neighboring tree at increments closer to center becomes much greater and lessens to random beyond 7 meters. Like Ripley's $\mathrm{K}$, the 1980 age class is the first occurrence where the pattern of growth becomes significantly clustered and greatest at the 1 meter increment and lessening to random within 6 meters. During the 1985 class, this extends to 7 meters and remains significant only to this level until the time of sampling.

On the southern site though, the pattern of establishment is markedly different. During the greatest period of establishment (1980) the likelihood of neighboring trees at the distance of 12 meters was the only significant increment. As additional trees established, there was a greater range of likelihood centered on the increments of 5 meters (4-5 m.) and 12 meters (9-15 m.) but not within distances less than that. This indicates that rather than new growth establishing near existing trees, the growth is considerably spaced and reliant on the common trait of the southern site; shelter from existing boulders.

The univariate $(K m(r))$ and multivariate marked $\left(L_{12}(r)\right)$ test statistics described in greater detail the influence that increasing basal area and species composition, respectively, would have on the pattern of establishment. Since complete spatial random (CSR) is equal to zero in these statistics again, a positive value indicates it would be a favorable influence on spatial arrangement and a negative value would 
indicate it has a detrimental effect on the pattern of growth if the value is greater (or less) than the confidence envelope. The univariate mark used during the first test was of average basal area of each stem at during each age class. This would determine if increasing basal area would significantly encourage or discourage neighboring growth or if the influence was within the confidence level for random, having no effect. It was hypothesized that at increments closest to the base that there would be an influence due to sheltering from environmental effects of temperature or desiccation by winter winds, but at no test increment on either sites did the size of the tree base prove to be statistically influential on the pattern of establishment when compared to the expected level of randomness at each location. This could be attributed to the relatively small basal area of the trees found at this location since they the majority established since 1970 and the tree size was not yet large enough to exhibit an influence on neighboring individuals either by sheltering or competition.

The multivariate test (fig. 7c) used species found at each location as the marked variable on the location of establishment to test whether or not there was significance in each species in how they were clustered at each distance. As this pattern of clustering was already confirmed by the Ripley's test of spatial autocorrelation, the multivariate test compares the likelihood at each point of a neighboring tree of the same type compared to all other types sampled, without using Monte Carlo simulations. Regarding the species types found on Bruce Mountain, the northern and southern sites share two species: Abies lasiocarpa and Pinus contorta. The northern site; however, also includes a large population of Picea engelmanii whereas the southern site includes one occurrence of Pinus albicaulis.

On the northern site, the pattern of species distribution remains largely similar after the majority of samples are established from 1975-1985. The majority of Abies Lasiocarpa and Picea engelmanii occur close to the center of the sampled point with greatest amount within 7 meters and decreasing rapidly with increasing distance. The number of observed stems of Pinus contorta increases with distance indicating a slightly greater than random occurrence throughout the plot, increasing with greater distances. Together, this shows that the large amount of clustering at short distances is largely comprised 
of Abies lasiocarpa and Picea engelmanii while Pinus contorta is clustered throughout and would appear to be less influenced by existing trees when establishing.

During the 1980 age class on the southern site, the greatest proportion of samples establishes and sets the structure for all species through to the time of sampling with some slight infilling close to the test locations in subsequent age classes. The likelihood of Pinus contorta and Abies lasiocarpa increases gradually with increasing distance in a similar fashion indicating that there is a greater than random occurrence of both throughout and as the distance from center increases, clustering in both species becomes collectively greater. The occurrence of Pinus albicaulis only on the southern site is represented by one stem that established in 1898 so the likelihood of a neighboring tree of this species remains negative throughout the age classes and, in general, highly unlikely to be found as a neighboring individual. Similar to the behavior of Pinus contorta on the northern site, clustering of Pinus contorta and Abies lasiocarpa appears to be less influenced by previously established trees and more reliant on another factor, which suggests the effect of topographic sheltering.

\section{DISCUSSION}

These statistics provide a description of how clustered growth between two test sites on an individual mountain can develop by different means based on the mechanism of facilitation. With the northern site, an initial advance of trees created areas of protection for subsequent establishment while the southern site relied on the existence of boulders that held moisture where it would have evaporated from the thinner exposed soils had it not been for their shelter. But these periods of advance across both locations began to a trend toward a climatic water deficit. From Elliott and Cowell (2015), sites in this location experience an annual water deficit when the cool season precipitation (fig. 1e) is proportionally less since Bruce Mountain consistently receives the majority of its total during these months. Having an adequate amount of summer precipitation as well as the ability to retain cool season moisture into the growing season would be of greatest importance to maintain growth. As this upslope advance was triggered by a prior period of climatic water deficit, the growth seen in this study was known to have taken place during 
a defined wet period resulting in a synchronous positive trend in radial growth between each site (fig. 3). As there was a slightly greater amount of average annual growth on the southern aspect in comparison to the north, consistent solar receipt on this slope could be responsible for the differences measured in the basal area index (BAI). If clustering happens closer to the base of neighboring vegetation on the northern trees it could provide insulation from snowpack and create lower temperatures for sheltered trees further into the growing season, equating to a lower amount of radial production, measured as BAI. With less solar receipt on the northern slope, ground temperatures would presumably remain lower and take longer to overcome the threshold needed for growth to begin (Körner 2004). On the southern slope, a greater solar receipt would encourage melting of snowpack earlier in the spring, raising the ground temperature and beginning the growing season, allowing for a longer period of annual growth. Yet, since the measured rate of production is remarkably similar since the 1970's, it shows that once trees are established, slope aspect appears to have minimal influence on tree growth rates above timberline within these two ecotones.

From the Ripley's K (fig. 7a) and the pair density function (fig. 7b) run on both locations, results show that while both sites are significantly clustered, they do so in distinctly different ways. The more concentrated grouping on the northern site reveals that there is much higher likelihood of subsequent tree establishment to occur within a few meters of each other. Beyond that, neighboring individuals are more sparsely found. As environmental stress from increases in mean annual temperature has been theorized to be a driver of clustered growth forms to provide shelter for direct sunlight (Elliott 2011), we see existing trees facilitating conditions allowing for new regeneration. This is supported by previous research that shows the importance of existing trees and topographic barriers in the development of linear hedges and establishment in the lee of boulders (Aftine and Malanson 2004; Bekker 2005; Resler et al. 2005; Resler 2006; Elliott 2011; Eliott 2012b). Given this, these results show clustering on the northern slope aspect creating a positive feedback of microclimatic conditions that encourage nearby growth. The likelihood of seedlings germinating in the moist shade of existing trees is higher than further apart. 
According to pair density function, the less concentrated clustering of the southern site is dependent on another factor, namely establishment in the lee of boulders. Given that the known recorded difference between the two groups of samples was how the southern samples were found in the shelter of topographic barriers; the clustering on the southern aspect becomes more descriptive of site conditions rather than the ability of a collective group to overcome a climatic regime. The observed distances in the occurrence of neighboring individuals appears to be the consequence of the spacing of the boulders allowing for growth. Also, considering the timing of establishment north to south, the north shows a first surge in upslope (1970) growth then two age classes that are subsequently more productive than the last which develop near existing samples. The southern site though, experiences one age class of growth that is remarkably greater than any other and little of the preceding or subsequent establishment shows a tendency to occur near other trees.

Since clustering on the southern aspect is so heavily correlated with the existence of topographic barriers, the shelter that they provide would seemingly create the best conditions where a seedling would be able to establish. Given that the northern aspect is also clustered and reliant on existing trees to accommodate further growth, it could be determined that the dry conditions found on Bruce Mountain have necessitated this clustered pattern to preserve moisture. In previous studies the result of increasing average temperature at treeline was often an increase in density rather than movement upslope (Danby and Hik 2007; Elliott 2012b). But consistent advance through the 1970, 1975, and 1980 age class indicates that drought may be impacting the trees on the north-facing slope greater than those of other locations.

Testing the impact of tree diameter on the spatial pattern of establishment from univariate analysis yielded no significant results (see Appendix). This could be due to the similar and young age of trees on the site, being that a great majority of available samples established after 1970. If using the diameter as a measure of tree size, the greater the size of the tree, one might expect a greater impact of sheltering or competition which would be expected as the trees mature. From the resulting statistics both sites show an increase in likelihood near the center of the random tested point, but this did not exceed the confidence envelope and should still be considered random. 
When testing the species as a controlling variable on the pattern of establishment (fig. 7c), there was a notable difference between the shared species of Abies lasiocarpa and Pinus contorta between the two sites. Since this statistic is a measure of likelihood from the center of the random point out to each distance increment, the larger distances include all occurrences at shorter distances adding up to a cumulative observed amount. Thus, if there are consistent occurrences along each increment, the greater the test distance, the greater the likelihood of locating the species. This is seen in the results of Abies lasiocarpa and Pinus contorta on the southern slope. The number of observations increases gradually with distance indicating that the species exists throughout with slightly higher concentrations within 7 meters and test increments beyond 10 meters. Since there were peaks in the pair density function at increments of 5 meters $(4-5 m)$ and 12 meters $(9-15 m)$, these intervals are responsible for this increase over distance. With the exception of the one stem of Pinus albicaulis, which is unlikely to be found at any distance, the likelihood of both Abies lasiocarpa and Pinus contorta are nearly identical indicating that neither species has a greater effect on the spatial pattern than the other (fig. 6b). Or, perhaps equally important, this could also indicate that another variable has a greater control over the location of establishment than species does (i.e. facilitation by topographic barriers).

On the northern slope, the observations of Abies lasiocarpa decreases dramatically beyond 7 meters, indicating that most are found at shorter increments and do not exist beyond that, decreasing in likelihood with increasing distance. Picea engelmannii shares a very similar result to Abies lasiocarpa while Pinus contorta increases gradually with distance. This shows that the clustering within 7 meters identified from the pair density function is primarily composed of Abies lasiocarpa and Picea engelmannii with less frequent occurrences of Pinus contorta throughout the site. Thus, on a site without topographic influences, two species (Abies lasiocarpa and Picea engelmannii) show an inclination to grow close to neighboring tress while Pinus contorta grows independently due to intolerance of shade during establishment. Additionally, the sample locations (fig. 5b) of Picea engelmannii show a greater amount of clustering at a lower elevation while Abies lasiocarpa is found throughout. This would attribute to the 
slightly less number of observations as random simulations would not observe it as prevalent across the site, but where it is found it grows in close proximity of neighboring trees.

These results are supported by their documented biological preference since germinating Picea engelmannii does not often survive in direct light which can inhibit photosynthesis. Instead they survive successfully under shade with adequate moisture (Uchytil 1991; Germino et al. 2002), which would be readily available on a northern aspect near established trees. Abies lasiocarpa has been known to tolerate all light conditions, often with a preference to shade. It is also known to have a more persistent root system than Picea engelmannii, but thrives in moist soil (Burns and Honkala 1990). This explains its prevalence on both sites, while tending toward more moist locations. It is able to establish in the direct light of the southern aspect as well as in clustered growth with Picea engelmannii (fig. 5b \& 6b), but still with a preference toward areas that retain moisture. Picea engelmannii rather, exists within a small area and highly concentrated with individuals of the same species (fig 5b). Pinus contorta germinates well in full sunlight, free from shade and competing vegetation (Burns and Honkala 1990). This is also well displayed by its occurrence on the southern aspect which has ample direct light (fig. 6b), and in how it does not show the same inclination toward clustering as Abies lasiocarpa and Picea engelmannii on the northern site (fig. 5b). Instead it appears to occur more infrequently and at farther distances from other species.

Using a Pearson correlation of each sampled species and grouped by 10-meter elevational increments, both sites shows that the synchronous trend in growth proves to be found throughout (Table 2). Correlations are nearly identical for similar elevation increments and within the shade-tolerant species that were found to be growing in spatial clusters. The slightly lower correlation between the lower limits of the shade-tolerant Abies Lasiocarpa and Picea engelmanii and the higher elevation, open-grown Pinus contorta may indicate a moisture limitation similar to that found by Salzer et al. (2014) as the site transitions from treeline to the outpost tree. As shown in average growth plotted for each species on the southern site (fig. 6d), the higher elevation samples of Pinus contorta result in a greater overall amount of elevations on this site for Abies Lasiocarpa. If moisture limitation is a controlling factor of higher elevation 
Table 2: Pearson Correlation of Tree Growth by Species and Elevational Gradient (10-meter)

\begin{tabular}{r|r|c|c|c|}
\cline { 2 - 5 } Site & \multicolumn{2}{|c|}{ Bruce Mountain North } & \multicolumn{2}{c}{ Bruce Mountian South } \\
\cline { 2 - 5 } Species & $A B L A$ & PIEN & PICO & ABLA
\end{tabular}

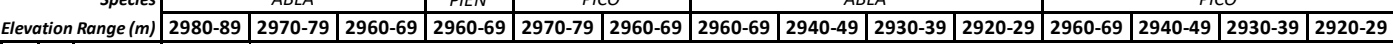

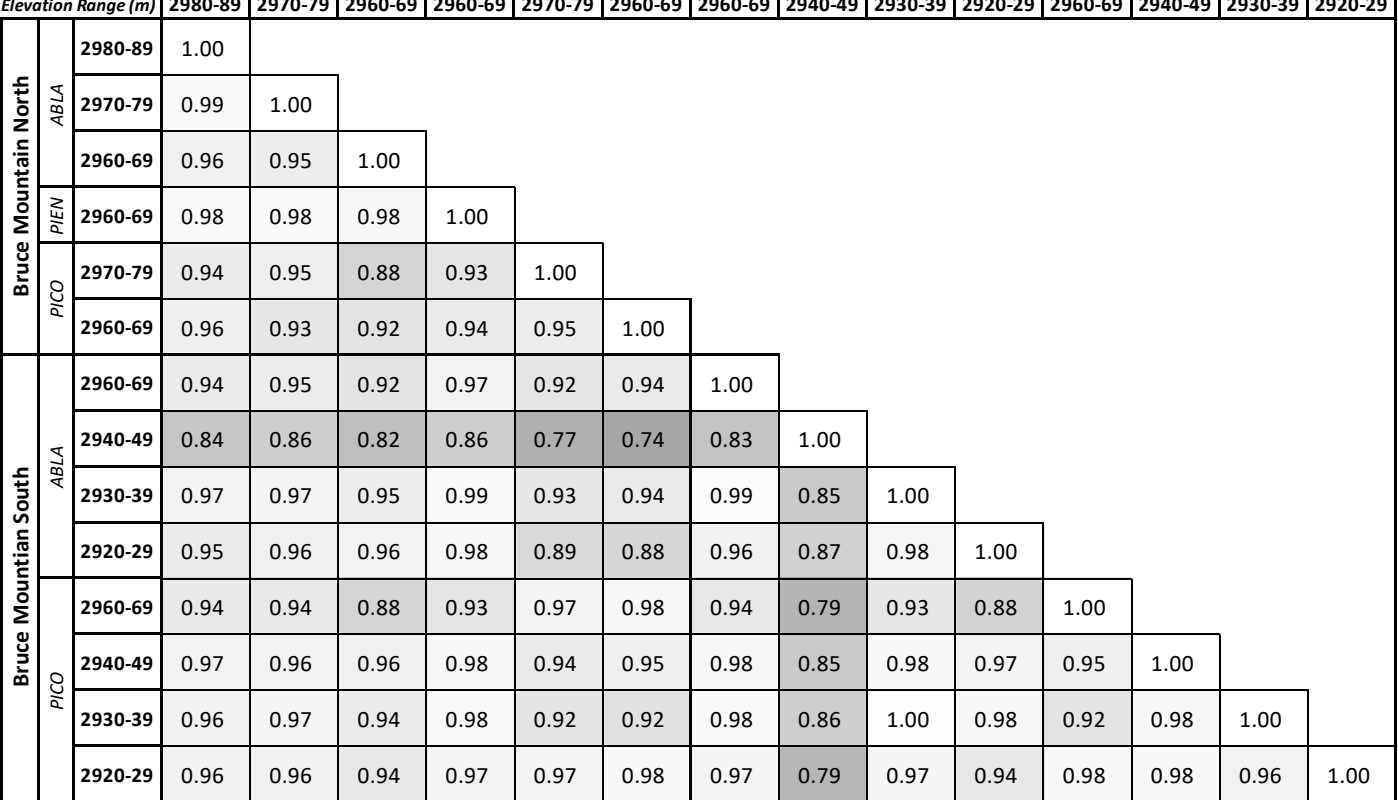

Table 2: Pearson correlation of average Basal Area Index (BAI) of tree species found at each site and divided into 10-meter increments in elevation. Tree species identified by standard four-letter code: ABLA-Abies lasiocarpa (Subalpine Fir) ; PIEN-Picea engelmannii (Engelmann Spruce); and PICO-Pinus contorta (Lodgepole Pine). All trees established prior to 1970 were not included, excluding the one sample of PIAL-Pinus albicaulis (Whitebark Pine). Shading based on lowest values found on the site. 
basal area compared to Abies lasiocarpa and Picea engelmanii, with less woody growth across all samples, this too displays a species-specific advantage for shade-intolerant species on this aspect. However, within similar elevational ranges on the northern site (fig. 5d) for Abies lasiocarpa and Pinus contorta result in similar rates of growth with a higher elevation sample of Abies lasiocarpa producing a much greater amount of woody growth which is possibly due the less direct solar receipt on this aspect and in an area with less competition.

\section{CONCLUSIONS}

In this study, the pattern of tree establishment on both the northern and southern aspects of Bruce Mountain indicate that a significant amount of spatial clustering has occurred since 1970; however, the cause of the density of the northern site is facilitated by preceding tree establishment while the southfacing slope is determined by the availability of topographically sheltered spaces. From these differing mechanisms, the patterns of growth begin to describe the availability of moisture found at each. At both locations, there was first an abrupt increase in growth above treeline followed by subsequent periods of continued establishment due to what has been theorized to be a bioclimatic threshold being reached where advance occurred at a previously undocumented rate (Danby and Hik 2007; Elliott 2011; Elliott 2012a; Elliott 2012b; Elliott and Cowell 2015).

While it was first hypothesized that sites on opposing aspect, from north to south, would create unique trends in radial growth, it became clear that the major differences in the growth record were from those trees that established long before the unprecedented upslope shift in the 1970's. The trend in basal production of all other individuals established following this shift shows the growth rates are almost perfectly aligned between sites. This was unexpected and is interpreted to emphasize the importance of feedbacks during the earliest periods of growth. Under differing conditions created by notably different amounts of solar receipt, they react synchronously to the air temperature and precipitation as long as they have the mechanism to retain moisture. The distance intervals between the occurrences of tree growth become descriptive of the most favorable growing conditions. 
Using age classes, the expectation was that it would provide insight into how the spatial pattern of tree growth developed over time to show the influence of sheltering by established trees. But often rather than an altogether shift from randomness to a defined structure, the periodic increases in establishment intensified the patterns that occurred within the first surge in colonization. The northern sites tended to establish within meters of one another and with additional establishment, trees filled in closer to the center of each tested location. Identifying the larger intervals between clusters of the southern site was more defined as each sheltered location was occupied. Thus, once bioclimatic conditions are such that upslope advance can occur, the subsequent growth seem to adhere to the same pattern of development.

As discussed by Elliott and Cowell (2015), when comparing the periods of establishment with period of upslope advancement over the length of the record, there is an uncoupling of biological processes shown where the timing of favorable radial growth occurs opposite to that of upslope advancement. Being that this study includes only those individuals that result from advancement above the historical timberline, the majority of which after the regime change around 1970, this growth has only occurred during a relatively wet period and following a significant dry period. A consistent period of relatively abundant moisture would be expected to encourage growth in the samples taken and this is what was recorded throughout. But these samples also lay out an important base of information leading into a period where the average annual temperature during the last ten years of record has risen at a greater rate than any other during this study (fig. 1b) and at an unprecedented level since 1950 (Salzer et al. 2014). Since average precipitation rates have remained constant during that time (fig. 1d), conditions are trending toward a future water deficit. Given that seedling production has followed periods of moisture stress, revisiting these sites in future years would allow an examination of how this would manifest in radial growth and further development in the spatial structure of trees on Bruce Mountain. Overall, uniform growth rates for saplings growing above timberline on both north- and south-facing slopes suggests that tree establishment may be more of a limiting factor to treeline advance than growth, although further study is needed to corroborate this. 
APPENDIX 
Bruce Mountain North

Ripley's K - L(r)

1975

L(r)

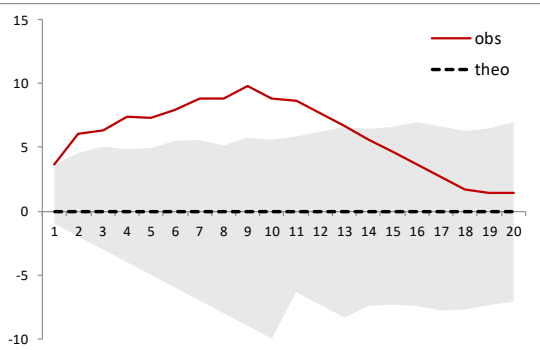

1980

$L(r)$

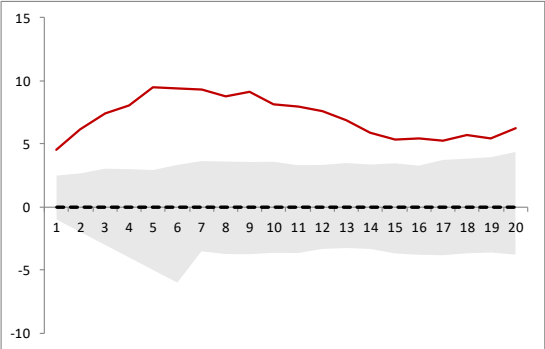

1985

$L(r)$

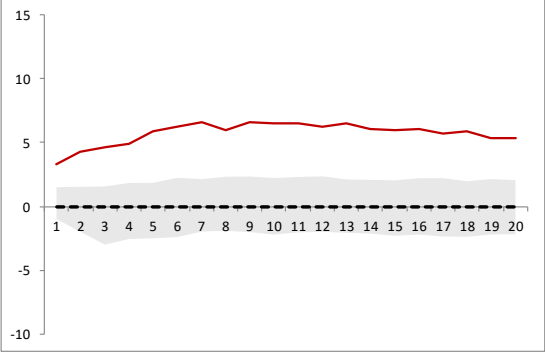

1990

L(r)

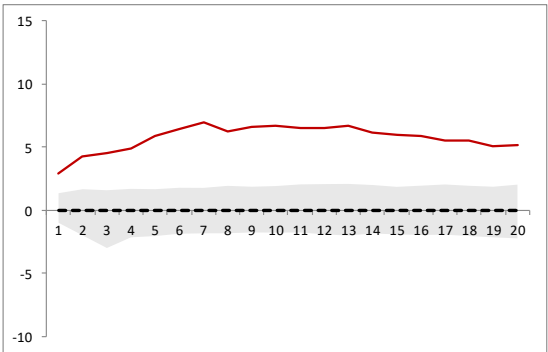

1995

L(r)

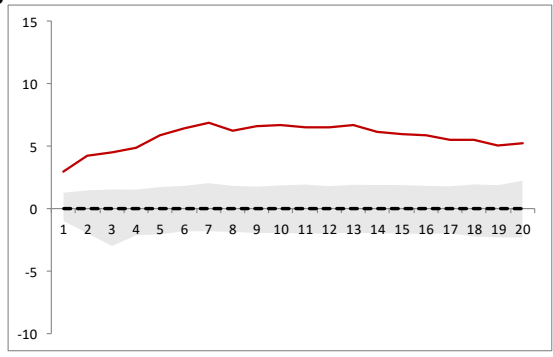

Distance ( $r$ )

Ripley's K - $L(r)$ : Using the $L(r)$ transformation of Ripley's $K$,

Monte Carlo simulations are run to to find the observed number of neighboring individuals from a random point to within a test distance using a 1-meter test interval, and CSR=0.
Pair Density Function

1975

$g(r)$

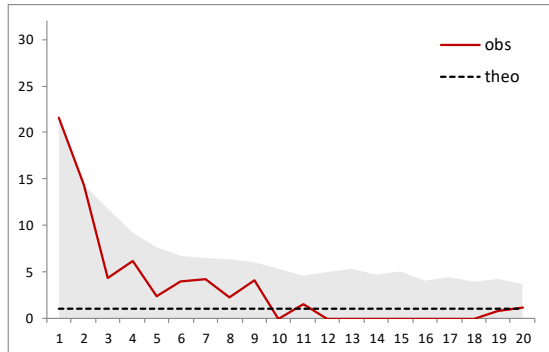

1980

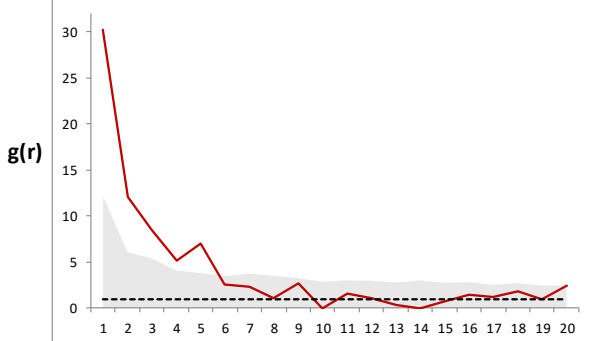

1985

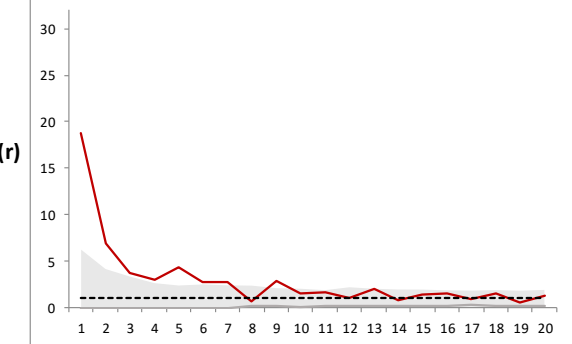

1990

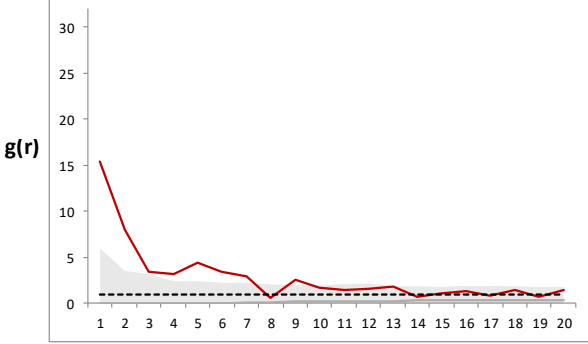

1995

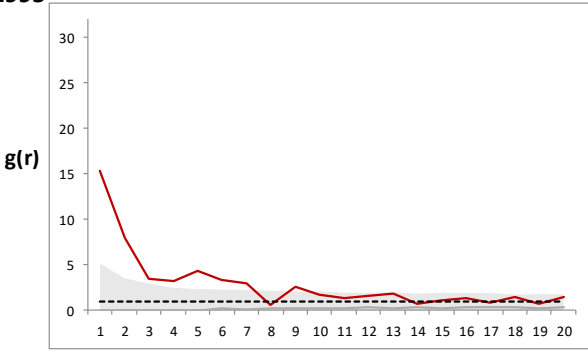

Distance ( $r)$

Pair Density Function - $\mathrm{g}(\mathrm{r})$ : Using the pair density function $(\mathrm{g}(\mathrm{r}))$, Monte Carlo simulations are run to to find the observed number of neighboring individuals at a specific test interval, 1-meter wide, projected in a ring surrounding a random point, with CSR $=0$. 
Bruce Mountain North

Univariate marked (tree diameter)
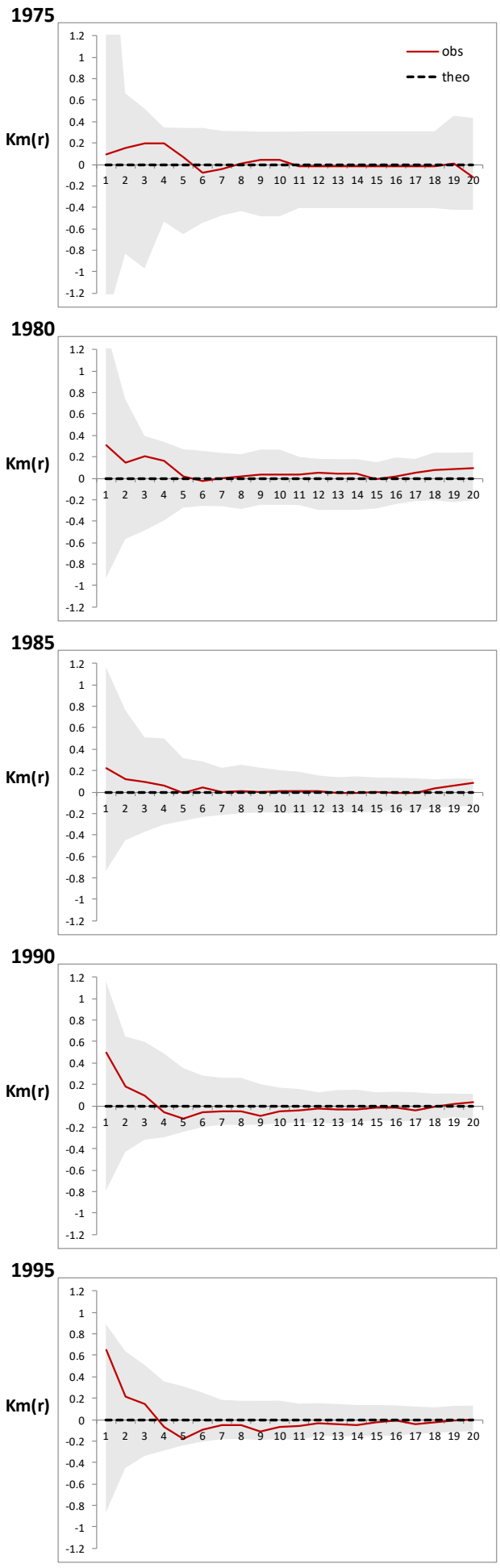

Distance ( $r$ )

Univariate marked $-\mathrm{Km}(\mathrm{r})$ : Under the $\mathrm{Km}(\mathrm{r})$ function, the stem diameter marked on the spatial pattern of establishment to identify the correlation that stem size has at increment (meters) on the likelihood of establishment, positive or negative $(1,-1)$ and $\mathrm{CSR}=0$

\section{Multivariate marked (tree species)}

1975

L12(r)

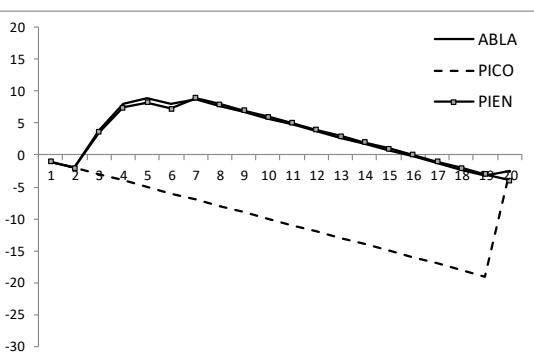

1980

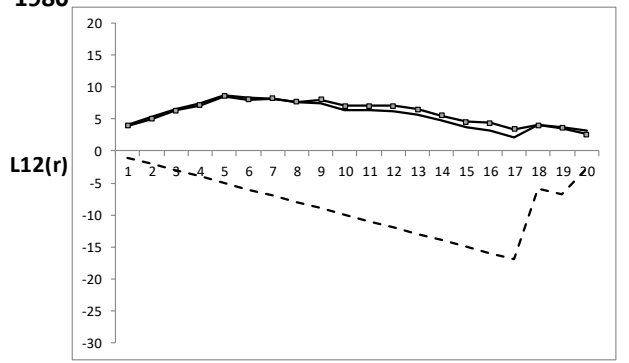

1985

L12(r)

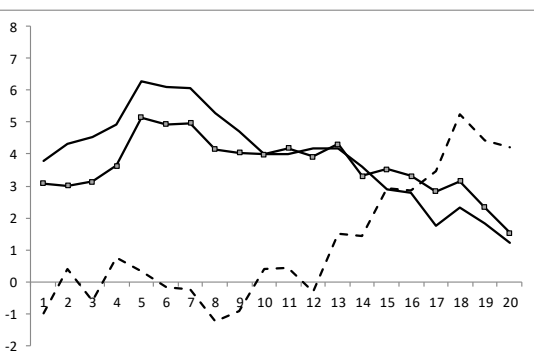

1990

L12(r)

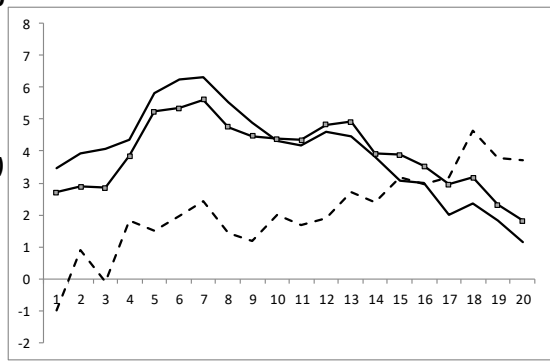

1995

L12(r)

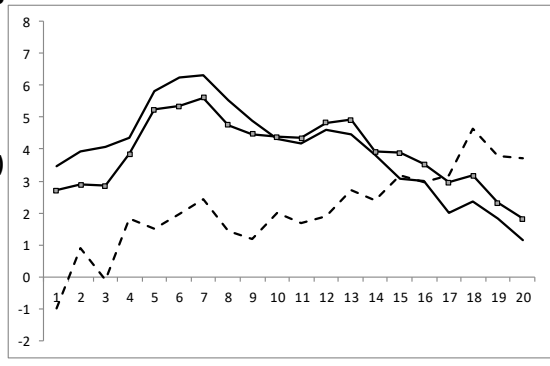

Distance ( $r$ )

Multivariate marked - L12(r): With the L12(r), each species is tested against the entire population of samples to identify the likelihood of each species establishing at that distance (meters) from a neighbor with $C S R=0$. Species identified: Abies Lasiocarpa (ABLA), Pinus contorta (PICO), and Picea Engelmannii (PIEN). 
Bruce Mountain South

\section{Ripley's K - L(r)}

1980

$L(r)$

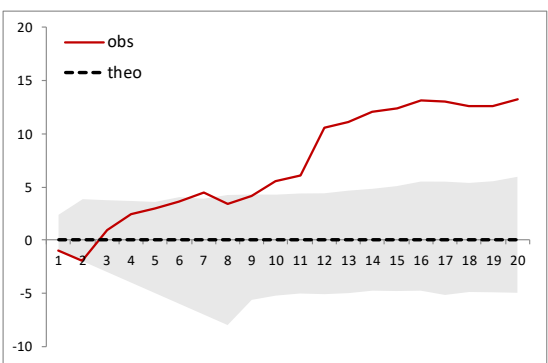

1985

L(r)

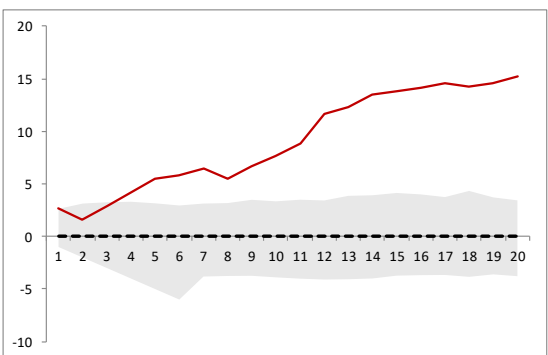

1990

$L(r)$

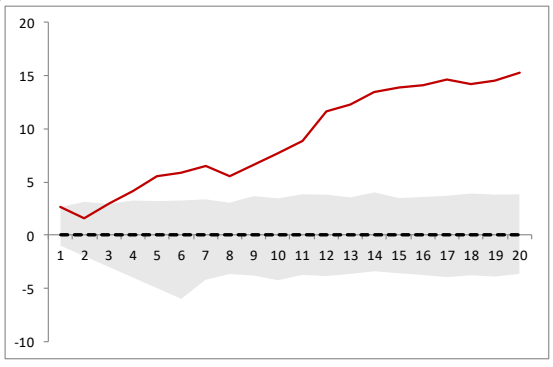

Distance ( $r)$

Ripley's $K$ - $L(r)$ : Using the $L(r)$ transformation of Ripley's $K$,

Monte Carlo simulations are run to to find the observed number of neighboring individuals from a random point to within a test distance using a 1-meter test interval, and CSR=0.
Pair Density Function
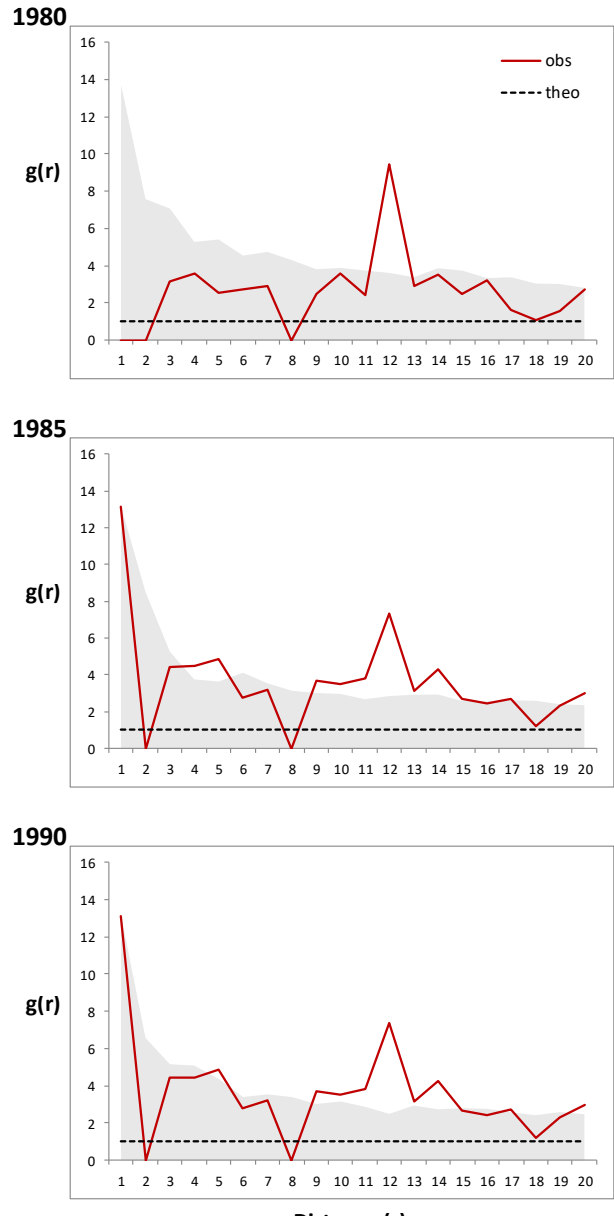

Distance $(r)$

Pair Density Function - $\mathrm{g}(\mathrm{r})$ : Using the pair density function $(\mathrm{g}(\mathrm{r}))$, Monte Carlo simulations are run to to find the observed number of neighboring individuals at a specific test interval, 1-meter wide, projected in a ring surrounding a random point, with $C S R=0$. 
Bruce Mountain South

Univariate marked (tree diameter)

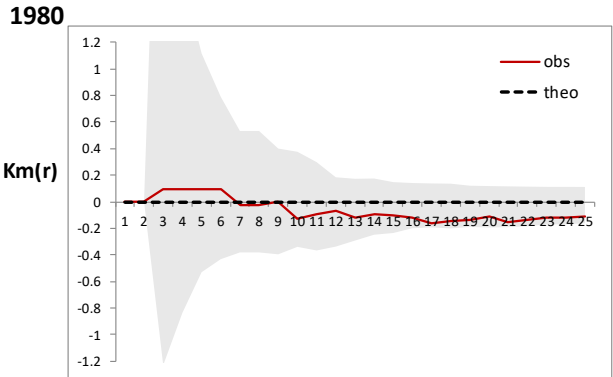

1985

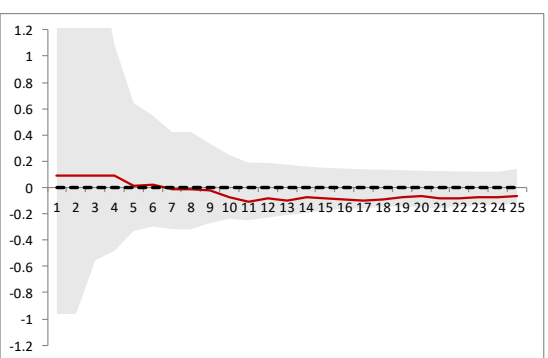

1990

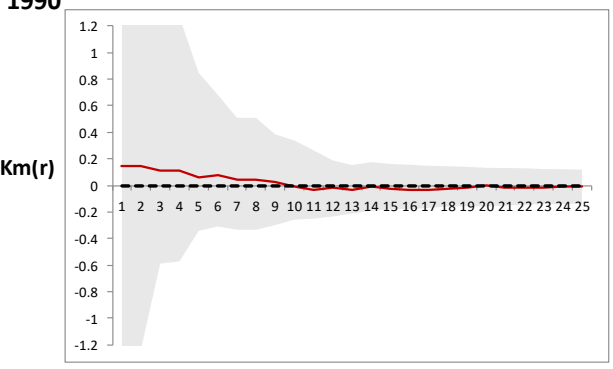

Distance ( $r$ )

Univariate marked - $\mathrm{Km}(\mathrm{r})$ : Under the $\mathrm{Km}(\mathrm{r})$ function, the stem diameter marked on the spatial pattern of establishment to identify the correlation that stem size has at increment (meters) on the likelihood of establishment, positive or negative $(1,-1)$ and $\mathrm{CSR}=0$.
Multivariate marked (tree species)

1980

L12(r)

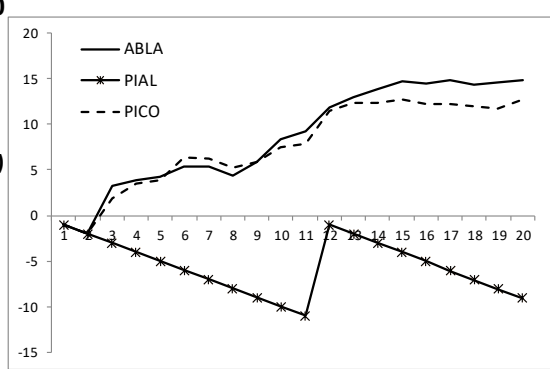

1985

L12(r)

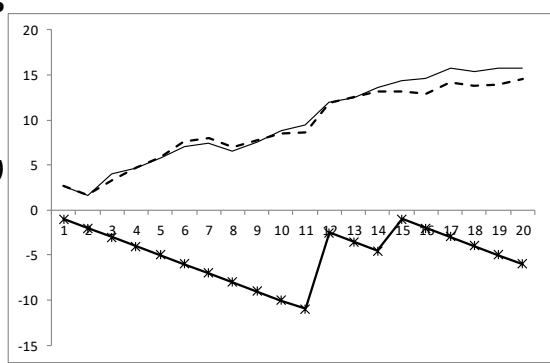

1990

L12(r)

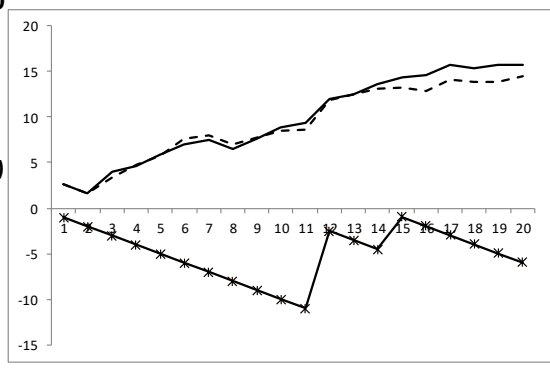

Distance ( $r)$

Multivariate marked - L12(r): With the L12(r), each species is tested against the entire population of samples to identify the likelihood of each species establishing at that distance (meters) from a neighbor with $C S R=0$. Species identified: Abies lasiocarpa (ABLA), Pinus Albicaulis (PIAL), and Pinus contorta (PICO). 


\section{REFERENCES}

Aftine, K. J. and G. P. Malanson (2004) Directional positive feedback and pattern at an alpine tree line. Journal of Vegetation Science, v. 15, pp.3-12.

Allen, C. D. and D. D. Breshears (1998), Drought-induced shift of a forest-woodland ecotone: Rapid landscape response to climate variation. Proceedings of the National Academy of Sciences of the United States of America (PNAS). v.95. pp.14839-14842.

Batllori, E. and E. Gutierrez (2008) Regional tree line dynamics in response to global change in the Pyrenees. Journal of Ecology, v.96, pp.1275-1288.

Bekker, M. F. (2005) Positive Feedback Between Tree Establishment and Patterns of Subalpine Forest Advancement, Glacier National Park, Montana, U.S.A. Arctic, Antarctic, and Alpine Research, v.37 (1), pp.97-107.

Besag, J. E. (1977). Discussion on Dr. Ripley's Paper. Journal of the Royal Statistical Society B, v.39, pp.193195.

Bourgeron, P. S. et al. (2015) The forest-alpine ecotone: a multi-scale approach to spatial and temporal dynamics of treeline change at Niwot Ridge. Plant Ecology \& Diversity, v.8(5-6), pp.763-779.

Bunn, A. G. et al. (2005). Topographic Mediation of Growth in High Elevation Foxtail Pine (Pinus Balfouriana Grev. Et Balf. Forests in the Sierra Nevada, USA. Global Ecology and Biogeography, v.14, pp.103-114.

Bunn, A. G. et al. (2011). Topographically modified tree-ring chronologies as a potential means to improve paleoclimate inference. Climatic Change, v.105, pp.627-634. 
Burns, R. M., and B. H. Honkala, tech. coords. (1990). Silvics of North America: 1. Conifers; 2. Hardwoods. Agriculture Handbook 654. U.S. Department of Agriculture, Forest Service, Washington, DC. v.2, 877 pages.

Butler, D. R. et al.(2007), Influences of Geomorphology and Geology on Alpine Treeline in the American West - More Important than Climatic Influence?. Physical Geography, v.28 (5). pp.434-450.

Danby, R. K. and D. S. Hik (2007), Variability, contingency and rapid change in recent subarctic alpine tree line dynamics. Journal of Ecology. v.95, pp.352-363.

Daniels, L. D. and T. T. Veblen (2004), Spatiotemporal Influences of Climate on Altitudinal Treeline in Northern Patagonia. Ecology, v.85 (5), pp.1284-1296.

Despain, D. G. (1973). Vegetation of the Big Horn Mountains, Wyoming, in relation to substrate and climate. Ecological Monographs, v.43, pp.329-355.

Diggle, P. J. (1983). Statistical Analysis of Spatial Point Patterns. Academic Press, London.

Duncan, R. P. (1991). Competition and the Coexistence of Species in a Mixed Podocarp Stand. Journal of Ecology. v.79, pp.1073-1084.

Elliott, G. P. and K. F. Kipfmueller (2010). Multi-scale Influences of Slope Aspect and Spatial Pattern on Ecotonal Dynamics at Upper Treeline in the Southern Rocky Mountains, U.S.A., Arctic, Antarctic, and Alpine Research, v.42 (1), pp. 45-56.

Elliott, G. P. (2011). Influences of 20th-century warming at the upper tree line contingent on local-scale interactions-evidence from a latitudinal gradient in the Rocky Mountains, USA. Global Ecology and Biogeography. v.20, pp.46-57.

Elliott, G. P. and K. F. Kipfmueller (2011). Multiscale Influences of Climate on Upper Treeline Dynamics in the Southern Rocky Mountains, USA: Evidence of Intraregional Variability and Bioclimatic Thresholds 
in Response to Twentieth-Century Warming. Annals of the Association of American Geographers, v.101(6), pp.1181-1203.

Elliott, G. P. (2012a). Extrinsic regime shifts drive abrupt changes in regeneration dynamics at upper treeline in the Rocky Mountains, USA. Ecology, v.93(7), pp.1614-1625.

Elliott, G. P. (2012b). The Role of Thresholds and Fine-Scale Processes in Driving Upper Treeline Dynamics in the Bighorn Mountains, Wyoming. Physical Geography, v.33(2), pp.129-145.

Elliott, G. P. and C. M. Cowell (2015). Slope aspect mediates fine-scale tree establishment patterns at upper treeline during wet and dry periods of the $20^{\text {th }}$ century. Arctic, Antarctic, and Alpine Research, v.47(4), pp.681-692.

Fajardo, A. and E. J. B. Mclntire (2012). Reversal of multicentury tree growth improvements and loss of synchrony at mountain tree lines point to changes in key drivers. Journal of Ecology, v.100, pp.782794.

Fryer, J. L. (2002). Pinus albicaulis. In: Fire Effects Information System, [Online]. U.S. Department of Agriculture, Forest Service, Rocky Mountain Research Station, Fire Sciences Laboratory (Producer). Available: http://www.fs.fed.us/database/feis/ [2015, September 17].

Germino, M. J. et al. (2002) Conifer seedling distribution and survival in an alpine-treeline ecotone. Plant Ecology, v.162, pp.157-168.

Goreaud F. (2000). Apports de l'Analyse de la Structure Spatiale en Foret Temperee a l'Etude et la Modelisation des Peuplements Complexes. Ph.D. thesis, ENGREF, Nancy, France.

Harsch, M. et al. (2009). Are treelines advancing? A global meta-analysis of treeline response to warming. Ecology Letters, v.12, pp.1040-1049. 
Harsch, M. A. and M. Y. Bader (2011). Treeline form - A Potential Key to Understanding Treeline Dynamics. Global Ecology and Biogeography, v.20, pp.582-596.

Holmes, R.L. Computer-assisted quality control in tree-ring dating and measurement. Tree Ring Bulletin. V.41, pp.69-78.

Holtmeier, F.K. and G. Broll (2005). Sensitivity and response of northern hemisphere altitudinal and polar treelines to environmental change at landscape and local scales. Global Ecology and Biogeography, v. 14, pp.395-410.

Holtmeier, F.K. and G. Broll, (2007). Treeline Advance - driving processes and adverse factors. Landscape Online, v.1, pp.1-33.

Holtmeier, F.K. and G. Broll (2012). Landform Influences on Treeline Patchiness and Dynamics in a Changing Climate. Physical Geography, v.33(5), pp. 403-437.

IPCC (2013) Summary for policymakers. Climate Change 2013: The physical science basis. Contribution of Working Group I to the Fifth Assessment Report of the Intergovernmental Panel on climate change. Cambridge University Press, Cambridge, pp.3-32.

Kipfmueller, K. F. and M. W. Salzer (2010). Linear trend and climate response of five-needle pines in the western United States related to treeline proximity. Canadian Journal of Forest Research, v.40 pp.134-142.

Körner, C. and J. Paulsen (2004). A world-wide study of high altitude treeline temperatures. Journal of Biogeography, v.31, pp.713-732.

Kullman, L. and L. Oberg (2009). Post-Little Ice Age tree line rise and climate warming in the Swedish Scandes: a landscape ecological perspective. Journal of Ecology, v.97, pp.415-429. 
Lamarche, V. C. (1973) Holocene Climatic Variations Inferred from Treeline Fluctuations in the White Mountains, California. Quaternary Research, v.3, pp.632-660.

Liang, E. et al. (2014). Is the growth of birch at the upper timberline in the Himalayas limited by moisture or by temperature? Ecology, v(95(9), pp.2453-2465.

Lloyd, A. and C. Fastie (2002). Spatial and Temporal Variability in the Growth and Climate Response of Treeline Trees in Alaska. Climatic Change, v. 52, pp. 481-509.

Lotwick H.W.; Silverman, B.W. (1982). Methods for Analysing Spatial Processes of Several Types of Points. Journal of the Royal Statistical Society B. v.44, pp.403-413.

Malanson, G. P. et al. (2007). Alpine Treeline of Western North America: Linking Organism-To-Landscape Dynamics. Physical Geography, v.28 (5), pp.378-396.

Mann, M. E. et al. (2008). Proxy-based reconstructions of hemispheric and global surface temperature variations over the past two millennia. Proceedings of the National Academy of Sciences, v.105 (36), pp.13252-13257.

Mitchell, V. L. (1976). The regionalization of climate in the western United States. Journal of Applied Meteorology, v.15, pp.920-927.

Moyes, A. B. et al. (2015). Moisture rivals temperature in limiting photosynthesis by trees establishing beyond their cold-edge range limit under ambient and warmed conditions. New Phytologist. v.207(4) pp.1005-1014.

Paulsen, J.; Weber, U. M.; and Körner, C. (2000). Tree growth near treeline: Abrupt or gradual reduction with altitude? Arctic, Antarctic, and Alpine Research, v.32, pp.14-20. 
Pelissier, R. and F. Goreaud (2015). ads Package for R: A Fast Unbiased Implementation of the K-function Family for Studying Spatial Point Patterns in Irregular-Shaped Sampling Windows. Journal of Statistical Software. v.63(6) pp.1-18.

PRISM Group, Oregon State University, http://www.prismclimate.org, created August 2, 2011.

R Development Core Team. (2009) R: A Language and Environment for Statistical Computing. R Foundation for Statistical Computing, Vienna, http://www.R-project.org.

Resler, L. M. et al. (2005) Topographic Shelter and Conifer Establishment and Mortality in an Alpine Environment, Glacier National Park, Montana. Physical Geography, v.26(2), pp.112-125.

Resler, L. M. (2006) Geomorphic Controls of Saptial Pattern and Process at Alpine Treeline. The Professional Geographer, v.56(2), pp.124-138.

Ripley BD (1977). Modelling Spatial Patterns. Journal of the Royal Statistical Society B, v.39, pp.172-212.

Salzer, M. W. et al. (2014). Changing climate response in near-treeline bristlecone pine with elevation and aspect. Environmental Research Letters, v.9, pp.1-9.

Shrestha, K. B.; A. Hofgaard; and V. Vandvik (2015). Recent treeline dynamics are similar between dry and mesic areas of Nepal, central Himalaya. Journal of Plant Ecology, v.8(4), pp.347-358.

Smith, W. K. et al. (2009). The Altitude of Alpine Treeline: A Bellwether of Climate Change Effects. Botanical Review, v.75, pp.163-190.

Stoyan, D.; Kendall, W.S.; Mecke, J. (1987). Stochastic Geometry and Its Applications. John Wiley \& Sons.

Uchytil, R. J. (1991). Picea engelmannii. In: Fire Effects Information System, [Online]. U.S. Department of Agriculture, Forest Service, Rocky Mountain Research Station, Fire Sciences Laboratory (Producer). Available: http://www.fs.fed.us/database/feis/ [2015, September 17]. 
Vaganov, E. A. et al. (1999). Influence of Snowfall and Melt Timing on Tree Growth in Subarctic Eurasia. Nature, v.400, pp.149-151.

Villalba, R. et al. (1994). Climatic Influences on the Growth of Subalpine Trees in the Colorado Front Range. Ecology, v.75(5), pp.1450-1462.

Wang, T. et al. (2006) Treeline dynamics in relation to climatic variability in the central Tianshan Mountains, northwestern China. Global Ecology and Biogeography, v.15, pp.406-415.

Wang, W. et al. (2013). No slope exposure effect on alpine treeline position in the Three Parallel Rivers Region, SW China. Alp Botany, v.123, pp. 87-95. 